\title{
Gestión de las organizaciones educativas con respecto a la implementación del Programa Nacional de Innovaciones Educativas en el Circuito 09, Dirección Regional de Educación San José-Norte, Costa Rica
}

\author{
Management of Educational Organizations Regarding the implementation of the National Programme of \\ Educational Innovation in the circuit 09, Regional Directorate of Education of North-San José, Costa Rica
}

\author{
Ivannia Calvo Gutiérrez' \\ Escuela de Física \\ Universidad de Costa Rica \\ ivanniacg@gmail.com
}

Recibido 17 de octubre 2012 • Aceptado 10 de diciembre 2012 • Corregido 16 de diciembre 2012

\begin{abstract}
Resumen. Este artículo corresponde a una investigación desarrollada en tres centros educativos de Moravia, San José, Costa Rica (circuito 09 de la Dirección Regional de Educación San José-Norte), para analizar la gestión de las organizaciones educativas respecto de la implementación del Programa Nacional de Innovaciones Educativas en las instituciones seleccionadas. El estudio se desarrolló bajo una modalidad cualitativa, utilizando enfoque deductivo combinado con un tipo de estudio denominado descriptivo, porque permite recopilar información científica, por medio de los siguientes objetivos: -Determinar los mecanismos de coordinación empleados en el desarrollo del Programa Nacional de Innovaciones Educativas; -Describir la estructura de organización del Programa Nacional de Innovaciones Educativas para su desarrollo en las tres instituciones seleccionadas; -Reconocer el proceso de planificación llevado a cabo para el desarrollo del Programa Nacional de Innovaciones Educativas; -Describir los sistemas de control empleados en la gestión del Programa Nacional de Innovaciones Educativas; y por último, -Describir las estrategias de evaluación implementadas en el desarrollo del Programa Nacional de Innovaciones Educativas. Los hallazgos proporcionaron conocimiento sobre el funcionamiento del Programa Nacional de Innovaciones Educativas desde la Administración de la Educación, considerando la creatividad y la innovación; componentes indispensables para enfrentar los retos de la sociedad global actual.
\end{abstract}

Palabras claves. Administración de la Educación, creatividad y gestión de la educación, innovación y gestión de la educación, conocimiento en organizaciones educativas, gestión de la educación, educación.

Máster en Ciencias de la Educación con énfasis en Administración Educativa de la Universidad de Costa Rica (UCR). Profesorado, bachillerato y licenciatura en la Enseñanza de las Ciencias de la Universidad Nacional (UNA). Actualmente se desempeña como docente de la Escuela de Física de la Universidad de Costa Rica y también como colaboradora del Programa Planetario. Asimismo es integrante de la Sección de Astronomía y Astrofísica, y del Centro de Investigaciones Espaciales (CINESPA) de la Universidad de Costa Rica. 
Abstract. This article is a research developed based on the study of three schools of Moravia, San José, Costa Rica (circuit 09 of the Regional Directorate of Education of North-San Jose), in order to analyze the management of educational organizations regarding the implementation of the National Programme of Educational Innovation in selected institutions. The study was conducted under a qualitative method, using the deductive approach combined with a type of study denominated descriptive, because allows to compile the scientific information through the following objectives: -Determine the coordination mechanisms employed at the development of the National Programme of Educational Innovation, -Describe the organizational structure of the National Programme of Educational Innovation for its development in the three selected institutions; -Recognize the planning process undertaken for the development of the National Programme of Educational Innovation; -Describe the control systems employed in the management of the National Programme of Educational Innovation, and finally, -Describe the evolutional strategies implemented in the development of the National Programme of Educational Innovation. The findings we found provide the knowledge on the functioning of the National Programme of Educational Innovation since the Educational Administration, considering the creativity and innovation as essential components to address the challenges of today's global society.

Keywords. Educational administration, creativity and management of education, innovation and management of education, knowledge of educational organizations, educational management, education.

\section{Introducción}

\section{Contextualización}

A lo largo de la historia, la sociedad actual ha gestado una serie de eventos y procesos políticos, económicos, culturales, científicos y tecnológicos, que se desarrollaron, y hoy continúan acrecentándose de distintas formas e intercambiando información entre sí.

Acontecimientos como dos guerras mundiales, el descubrimiento de la estructura molecular del ácido desoxirribonucleico (ADN), revoluciones políticas e industriales, la Teoría de la Relatividad General de Einstein, la clonación, la caída del muro de Berlín, el asesinato de John F. Kennedy, la guerra de Vietnam, el lanzamiento del Sputnik, la llegada del ser humano a la Luna, los bombardeos atómicos sobre Hiroshima y Nagasaki, así como la exploración espacial, han marcado a la humanidad desde distintos puntos de vista, en diferentes periodos, provocando entre otros cambios, una reestructuración en el modo de producción, pues la revolución de la tecnología de la información ha permitido la implementación de procesos fundamentales de reestructuración del sistema capitalista, desde la década de los ochenta (Castells, 2000).

Así, en virtud de lo anterior, es evidente que uno de los aspectos que provoca fluctuaciones en una sociedad en sus distintos contextos, lo constituyen las circunstancias políticas y económicas que rodean a un país, y que suelen desembocar, en algunas ocasiones de manera 
negativa en aquellos sectores caracterizados por ser, entre otros, socialmente vulnerables, lo cual es destacado por Ornelas (2007):

Se trata, en todo caso, de repensar y reconceptualizar el desarrollo vinculando la economía con la política para volver a dar así el sentido social original, y que nunca debió perder, a la economía, actividad que carece de objetivo en sí misma y, por el contrario, es un proceso social dirigido y orientado a erradicar flagelos sociales como la pobreza, el desempleo y la desigualdad, entre otros muchos, orientación que le fue arrebatada por el pensamiento neoliberal. (p. 7)

De este modo, con la formación integral en un accesible entorno democrático, los individuos, lejos de quedar excluidos del sistema educativo, adquirirán las herramientas para incorporarse a una sociedad globalizada, y tendrán la capacidad de discernir entre las múltiples opciones de información que les proporcione la tecnología de la información y el conocimiento.

En consecuencia, la administración de la educación, a través de distintas funciones, puede promover cierto dinamismo en la comunidad educativa, respecto del medio en el que se encuentra, tal y como oportunamente lo expresa Drucker (1999a) al manifestar que se pueden definir las pautas para que la enseñanza y la escuela puedan responder a las realidades de la sociedad del conocimiento.

Ante este panorama, es claro que el sistema educativo costarricense actual, mediante la administración de la educación, trate de mitigar todos aquellos factores que inciden en la sociedad, por lo cual es imprescindible que preste atención a lo que sucede, en primera instancia, en el ámbito educativo, con el fin de propiciar una mejoría en las condiciones bajo las cuales opera la educación costarricense, tales como coadyuvar a promover una justa, razonable e importante inversión en educación, la intensificación de las estrategias necesarias para promover, entre otras, las condiciones laborales de los educadores, disminuir la deserción, e impulsar la calidad del proceso enseñanza-aprendizaje. De esta forma, se procura responder a uno o varios desafíos y demandas, algunos de las cuales son producto de una constante incursión política, económica, científica y tecnológica, según lo recomienda el Programa Estado de la Nación en Desarrollo Humano de 2005, citado por Garbanzo y Orozco (2007):

- universalizar la cobertura preescolar y secundaria,

- mejorar la calidad del sistema educativo,

- reducir la reprobación y mejorar la eficiencia,

- retener a los estudiantes y las estudiantes del sistema educativo,

- disminuir brechas socioespaciales,

- ampliar la inversión en educación,

- mejorar las precarias condiciones de trabajo de las docentes y los docentes, 
- mejorar la rectoría del sector,

- reforma institucional,

- fortalecer el sistema de monitoreo y evaluación,

- fortalecer la investigación educativa,

- reforzar el papel de las universidades públicas como agentes, de movilidad social,

- mejorar el monitoreo y el control de calidad de la enseñanza universitaria,

- fortalecer el vínculo entre la generación del conocimiento y su aplicación al desarrollo. (p. 98)

Es evidente que se requiere diseñar toda una articulación entre distintos sectores del país, tales como el político, económico, social, cultural y educativo, en aras de promover ciertos cambios en los niveles institucionales que conlleven a mejorar la calidad del sistema educativo costarricense y que impliquen la disminución de brechas sociales y, además impulsar estudios en educación y procesos de evaluación continua de la calidad educativa, en medio de la Sociedad de la Información y el Conocimiento.

\section{Justificación del problema y su importancia}

Se han considerado parámetros relacionados con la gestión de la calidad en las organizaciones educativas y, por lo tanto, con la administración de la educación, los cuales se plasman en distintas áreas temáticas como lo son: la gestión estratégica, el liderazgo directivo, la gestión curricular y la gestión de las competencias profesionales (Programa Estado de la Educación, 2011).

Además, articulando en el nivel educativo la creatividad y la innovación, administradas en forma eficiente (tomando en cuenta el contexto en el que se ubica un centro educativo), es posible una mejor calidad educativa. Con todo lo que esto significa, se espera que con la implementación de programas y proyectos innovadores se obtengan ventajas no solo en términos económicos y curriculares, sino también en la incentivación de una gestión ágil, eficiente y eficaz, que conlleve a la máxima manifestación de la calidad de la educación del sistema educativo público costarricense.

Por eso en este estudio surge un interés por indagar sobre la adecuada gestión de la innovación en el nivel educativo, así como su conexión con el Programa Nacional de Innovaciones Educativas. En este mismo sentido, surge también un particular interés por indagar sobre la forma a través de la cual una alternativa innovadora (como el mencionado programa que impulsa la creatividad y la innovación), es administrada, con la finalidad, de mejorar tanto la calidad como la aplicación de distintos procesos de planificación, coordinación y toma de decisiones. 
Para ello, se plantean los siguientes objetivos, generales y específicos, que dan lugar a la investigación:

\section{Objetivo general}

Analizar la gestión de las organizaciones educativas respecto de la implementación del Programa Nacional de Innovaciones Educativas en tres instituciones del circuito 09 de la Dirección Regional de Educación San José Norte.

\section{Objetivos específicos}

- Determinar los mecanismos de coordinación empleados en el desarrollo del Programa Nacional de Innovaciones Educativas.

- Describir la estructura de organización del Programa Nacional de Innovaciones Educativas para su desarrollo en las tres instituciones seleccionadas.

- Reconocer el proceso de planificación llevado a cabo para el desarrollo del Programa Nacional de Innovaciones Educativas.

- Describir los sistemas de control empleados en la gestión del Programa Nacional de Innovaciones Educativas.

- Describir las estrategias de evaluación implementadas en el desarrollo del Programa Nacional de Innovaciones Educativas.

\section{Fundamentación teórica}

\section{Administración de la educación}

Debido a las características que presenta como disciplina científica, el objeto de estudio de la administración de la educación, son las organizaciones educativas, pues se basa en la interacción o combinación sistemática de varias disciplinas fundamentales: las Ciencias de la Educación, la teoría administrativa general, y otras disciplinas, como la Economía, la Psicología, la Sociología, las Ciencias Políticas y el Derecho, entre otras (Salas, 2003).

Por eso, es conveniente que las organizaciones de la actualidad fortalezcan ciertas habilidades para alcanzar sus objetivos, y considerando el contexto plasmado anteriormente, la 
innovación parece ser una de las más importantes, debido a que por medio de esta se pueden articular muchos aspectos de la organización: "Pero hay una habilidad esencial que toda organización -y no sólo los negocios- necesita: innovación" (Drucker, 1999b, p. 170).

Así, es imprescindible que, en el contexto en el que se desarrolla el sistema educativo público costarricense, los profesionales de la administración de la educación de la sociedad actual, consideren el concepto de gestión de Drucker (1999a), que significa proporcionar el conocimiento o el saber para visualizar la forma del conocimiento existente, que se puede aplicar para producir resultados. Además, el conocimiento se aplica a la innovación sistemática, lo cual es la revolución de la gestión.

En efecto, es importante que toda persona responsable de una organización educativa que impulse la innovación en la institución a su cargo, considere la articulación de la división del trabajo. Existen seis mecanismos de coordinación tales como la adaptación mutua (que requiere un sencillo proceso de comunicación informal), supervisión directa (donde una persona da órdenes a otros cuando un cierto número de personas deben trabajar juntas), la estandarización del proceso de trabajo (en este sentido, se debe programar el trabajo de distintas personas para coordinar de una forma rigurosa), la estandarización de los resultados (lo cual conduce a la especificación de resultados), la estandarización de las habilidades (en donde un trabajador aplica los conocimientos que tiene, en el trabajo que realiza, de modo que la coordinación se logra cuando cada trabajador sabe lo que se espera de él) y la estandarización de normas (lo cual significa que los trabajadores comparten una serie de creencias comunes y logran coordinarse a partir de este hecho). Estos mecanismos pueden considerarse como los elementos básicos de una estructura, pues mantienen la cohesión de las organizaciones. No obstante, algunas organizaciones prefieren un mecanismo más que otros, pero todas aplican (en mayor o menor grado), estos mecanismos (Mintzberg y Quinn, 1993).

Por otra parte, la estructura de la organización es el conjunto de puestos o de departamentos, que orienta la conducta de individuos y grupos, para que se logren los objetivos y metas planteadas de la organización (Ivancevich, Lorenzi, Skinner y Crosby, 1997).

El proceso de planificación consta de seis etapas que implican acciones como evaluar las condiciones actuales (que puede ser basándose en los objetivos o tendencias; o recopilando información de la organización), determinar objetivos y metas (especificando las condiciones deseadas a futuro; o los estados o condiciones futuras que contribuyen al cumplimiento de la finalidad de la organización), establecer un plan de acción (o medios específicos prescritos para el logro de los objetivos; y también se debe contar con la previsión), asignar recursos (financieros, físicos, humanos, tiempo u otro de la organización), ejecución (lo cual se relaciona con la delegación de tareas, a la acción impulsada por los objetivos y con la obtención de datos 
para retroalimentación) y control (lo cual incluye todas las actividades de gestión que tienen por objeto definir si los resultados obtenidos corresponden a los propuestos) (Ivancevich et al., 1997).

Los sistemas de control se basan en las medidas operativas, pues controlan las operaciones a través del producto terminado, y permiten a los trabajadores evaluar los procesos a medida que se desarrollan (Ivancevich et al., 1997).

Por otra parte, las estrategias de evaluación constituyen los medios, acciones o atributos para verificar si efectivamente se cumplieron los objetivos o metas propuestos, emitiendo un juicio valorativo durante y después de la aplicación, en un ciclo de intervención social (David, 2008; Fernández-Ballesteros, 2001).

Bajo este orden de ideas, es imprescindible que las autoridades competentes costarricenses presten atención a la forma a través de la cual algunas organizaciones educativas son administradas, de modo que se propicie no solo cierto dinamismo, sino también los mecanismos para fortalecer la calidad educativa, como lo exponen Garbanzo y Orozco (2010):

Ante tales circunstancias, es impostergable para la educación costarricense que sus administradores de la educación, además de dinamizar las organizaciones que dirigen, promuevan la innovación y el cambio como herramientas estratégicas que permitan atender con éxito las desafiantes y complejas demandas del contexto, asegurándole así al sistema educativo mejores niveles de calidad educativa, lo cual es y debe ser una tarea permanente de la educación en sus diferentes ámbitos en respuesta a sus fines y objetivos. (p. 20)

De esta forma, empleando distintas estrategias dinámicas, la administración de la educación responde, en el contexto costarricense, a las demandas de la sociedad global actual.

\section{Calidad de la educación}

La calidad, en términos generales, es un parámetro sumamente complejo, por cuanto implica la interacción de una serie de elementos y procesos, para prestar un servicio, según lo apunta Correa de Molina (2004):

Una concepción de calidad, entendida como una realidad compleja, integral y holística, implica armonizar, tejer una urdimbre con los diferentes aspectos que componen la dialéctica institucional: eficacia en la prestación del servicio, mediante procesos eficientes y satisfactorios, tanto para los usuarios directos e indirectos como para el personal de la institución responsable de lograrla. (p. 61) 
Por esta razón, es importante que el profesional de la administración de la educación considere la importancia de los recursos con los que dispone, siendo según Chiavenato (2000), el humano el más importante. De ahí, que la pertinencia de impulsar, desde la gestión, distintas estrategias innovadoras, y a la vez administrarlas correctamente, a través de las cuales se propicie, entre otros, el trabajo en equipo, para mejorar tanto el desarrollo de cada persona, como el de la organización como un todo.

Evidentemente, para que un proyecto se desarrolle satisfactoriamente en el centro educativo, debe contar con creatividad en el nivel institucional (Correa de Molina, 2004). Es así como la creatividad, marco de la sociedad global actual, adquiere una función sumamente importante, y si se combina con la innovación, el resultado que provoca en una organización educativa, así como en las personas que la conforman, es por añadidura, sumamente espectacular. De esta manera, con la creatividad y la innovación, es posible potencializar la calidad en un centro educativo, a partir de ideas que en primera instancia son irrelevantes, tal y como señala Whitaker (1998) a continuación:

La gestión de la calidad parte de la idea de que cualquier cosa puede hacerse mejor de lo que es, y de la noción de que toda mejora cuenta, aunque a primera vista sea insignificante. Lo que sugiere que ningún aspecto del proceso de gestión es lo bastante irrelevante como para no merecer atención, y que precisamente es la atención a los pequeños detalles donde con frecuencia se encuentra la llave del éxito. Para demasiadas organizaciones, cambiar se asocia con grandes gestos y reestructuraciones profundas. Sin embargo, lo que tiene más éxito es con frecuencia emprender un camino de pequeñas y sutiles mejoras de lo que ya de por sí es bueno y exitoso. (p. 187)

De esta manera, desarrollar la calidad educativa implica, inminentemente, una profunda articulación de distintas herramientas estratégicas, desarrolladas desde la administración de la educación.

\section{Creatividad e Innovación}

A lo largo de la historia, la humanidad ha gestado muchos procesos y eventos. Entre ellos, los que adquieren mayor atención desde el punto de vista de la creatividad, son los culturales, científicos y tecnológicos. Sin embargo, de la antigüedad, el movimiento cultural que captura la atención desde la perspectiva de la creatividad es el Renacimiento.

Pero más que una inspiración, se requiere trabajo, concentración, capacidad de discernir, criticidad y constancia por parte del individuo, tal y como seguidamente lo manifiesta Velasco (2007): 
Howard Gardner, estudioso incansable de la creatividad, confirma este hecho: en su interesante investigación Mentes creativas. Una anatomía de la creatividad (1995), estudia siete casos de creadores escogidos de diversos campos, comprobando que la disciplina y la constancia son elementos fundamentales que permiten que el creador dé frutos en el ámbito donde se desempeña. (p. 28)

Por su parte, la innovación es distinta a la creatividad. Implica que el equipo de trabajo de una organización labore en conjunto, introduciendo ideas o procedimientos que provoquen un impacto positivo, mejorando el desarrollo de la organización, según lo exponen Maidagán, Iñaqui, Garagalza y Arrizabalaga (2009):

Algunas innovaciones han cambiado el rumbo de la historia. Smith organiza el paisaje conceptual del proceso de innovación, afirmando que dicho proceso incluye las actividades para solucionar problemas y la invención, que incluye, a su vez, las actividades para solucionar problemas, la creación de ideas (producción mental de posibilidades o alternativas que se tienen que realizar en varios puntos en la mayoría de los episodios de la resolución de problemas) y el diseño (desarrollo o invención de cosas complejas) (2003: 348-349). La capacidad de generar ideas y de realizarlas se atribuyen, por lo general, a la creatividad de la persona. (p. 22)

Por esta razón, en el marco de la sociedad global actual, impulsar desde la gestión la creatividad y la innovación en las organizaciones educativas, desembocará ineludiblemente, en el desarrollo y producción de conocimiento.

\section{La Tecnología de la Información y la Comunicación (TIC) y Sociedad de la Información y el Conocimiento (SIC)}

Hoy, la educación está experimentando transformaciones sociales que definen su desarrollo y si se considera la fuerza con la cual actúa la SIC, el panorama es complejo: "Y esto es lo que ocurre ahora que estamos entrando en la "sociedad de la información"; momento de profundos cambios socioculturales que exigen cambios educativos adecuados"(Majó y Marqués, 2001, p. 106). Tales cambios, se empiezan a manifestar en las organizaciones educativas.

En virtud de lo anterior, las TIC ejercen una función en los centros educativos, no solo porque, evidentemente, son una de las organizaciones en las cuales, por su naturaleza, se produce conocimiento, sino que además, en ellas se pueden implementar y desarrollar la creatividad y la innovación en distintas áreas como las administrativas, curriculares, financieras, informativas y otras; que se pueden gestionar usando los portales educativos, tal y como se apunta a continuación: "La utilidad de los portales educativos se deriva de los servicios que ofrecen y del hecho de estar accesibles en cualquier momento y lugar a través de Internet" 
(Majó y Marqués, 2001, p. 198). Así, se emplean distintos recursos, desde la Administración de la Educación, para impulsar entre otros, el desarrollo científico-tecnológico, a través de la creatividad y la innovación.

\section{El Programa Nacional de Innovaciones Educativas}

Es importante promover un proceso de gestión que fomente aspectos como el compromiso, la comunicación, las interacciones, la iniciativa y las respuestas a los desafíos (Whitaker, 1998). Estos aspectos impulsarán, entre otras acciones una adecuada articulación entre los distintos componentes implícitos al centro educativo interesado en participar en el Programa Nacional de Innovaciones Educativas, como el director o directora del centro educativo, el docente, el profesor de informática, el coordinador de recursos tecnológicos, los estudiantes, el comité de innovación institucional (el cual velará para que se cumpla el proceso de innovación institucional, por medio del adecuado uso de la tecnología, aplicados a procesos educativos), la sostenibilidad, la metodología, el plan de estudios (con la incorporación de tecnologías para colegios académicos), así como los Talleres de Innovación Tecnológica (MEP, 2006). Por lo tanto, la articulación de cada uno de estos componentes desde la Administración de la Educación es pertinente, para que las organizaciones educativas costarricenses respondan a las demandas de la sociedad global actual.

\section{Referente metodológico}

La naturaleza metodológica utilizada en esta investigación es cualitativa, por considerarse que: "El enfoque cualitativo busca llegar al conocimiento "desde dentro" (Stromquist, p. 86), por medio del entendimiento de intenciones y el uso de la empatía" (Barrantes, 2004, p. 68). Por eso se utilizó, además, un enfoque deductivo, para tener empatía con los sujetos involucrados, al analizar, desde la gestión, la implementación del Programa Nacional de Innovaciones Educativas, lo que conduce a intercambiar información con las personas involucradas.

Considerando la naturaleza de los objetivos planteados, esta investigación se caracteriza por aplicar un tipo de estudio denominado descriptivo, porque es la forma más adecuada de estudiar el impacto de la implementación de innovaciones (mediante el software libre), en la gestión de las organizaciones educativas, y donde las técnicas de las cuales se nutre, permiten profundizar (en el marco de un proceso caracterizado por la innovación y creatividad), en el análisis de la gestión de las organizaciones educativas, la implementación del Programa Nacional de Innovaciones Educativas. 
En el estudio descriptivo se selecciona una serie de cuestiones, midiendo cada una independientemente, para describir lo que se investiga (Hernández, Fernández y Baptista, 1998). En consecuencia, se trata de estudiar la información recopilada (según los objetivos planteados), con base en los instrumentos meticulosamente confeccionados y diseñados, aplicados en las instituciones seleccionadas.

Es por esta razón, que en este estudio se utilizará el método científico, debido a que requiere procedimientos sistemáticos y ordenados; tal y como lo manifiesta Barrantes (2004) "(...) es un procedimiento para tratar un conjunto de problemas, o un ciclo entero de la investigación en el marco de cada problema del conocimiento" (p. 27). Debido a los distintos condicionantes plasmados en el marco teórico, y, por ende, las características de esta investigación, se manifiestan, entre otros, intercambios de distintos aspectos entre las partes involucradas, para conocer lo que ocurre según los objetivos planteados.

Al utilizar el método científico, se garantizará que los instrumentos aplicados proporcionen tanto confiabilidad, pues el instrumento debe producir medidas constantes dado un mismo fenómeno; como validez, generando medidas adecuadas y precisas para obtener conclusiones correctas (Barrantes, 2004). Lo cual es de especial interés en este estudio, por cuanto fue posible obtener información de los sujetos que participaron, en relación con el desarrollo de la creatividad y la innovación, por medio de la implementación del Programa Nacional de Innovaciones Educativas.

\section{Población}

La población de este estudio se conformó por el profesional en administración de la educación, el funcionario responsable (que funge como el encargado a través del cual el Programa Nacional de Innovaciones Educativas se implementa en el centro educativo); y la persona que supervisa el circuito 09; bajo cuya responsabilidad están las instituciones que participan en este estudio; así como el asesor de informática educativa asignado al Programa de Innovaciones Educativas.

Los centros educativos se seleccionaron porque participan en el Programa Nacional de Innovaciones Educativas, lo cual por lo acotado en los apartados anteriores, es esencial para esta investigación; considerando el contexto en el cual se desarrolla la innovación, en la sociedad costarricense actual.

Por la naturaleza del estudio, así como por la cantidad de personas, no se tomó muestra, si no que se consideró a la totalidad de sujetos involucrados, lo cual se sintetiza en la siguiente tabla: 
Tabla 1

Distribución de funcionarios que participan en este estudio

\begin{tabular}{lc}
\hline \multicolumn{1}{c}{ Funcionarios participantes } & Total \\
\hline Directores de centros educativos participantes del Programa de Innovaciones & 3 \\
$\begin{array}{l}\text { Funcionario responsable (a través de quien se coordina el programa nacional de innovaciones } \\
\text { educativas en el centro educativo) }\end{array}$ & 3 \\
Supervisor & 1 \\
Asesor asignado al Programa & 1 \\
\hline
\end{tabular}

Fuente: Elaboración propia, 2011

A las instituciones que participaron en este estudio, se les asignó la siguiente nomenclatura:

- Liceo Bilingüe de la Trinidad de Moravia: Colegio 1

- Liceo Abelardo Bonilla: Colegio 2

- Liceo Laboratorio-UCR-Emma Gamboa: Colegio 3.

Es importante aclarar que para el caso del colegio 2, el Programa Nacional de Innovaciones Educativas, se canaliza a través de una responsabilidad compartida, entre un analista y un docente de innovación; de los cuales, para este estudio, se seleccionó al analista (o profesional de informática).

\section{Operacionalización metodológica}

Por las razones planteadas, se propone la siguienteoperacionalización metodológica, donde se resume la categoría de análisis, definición conceptual, la conceptualización y los indicadores; relacionados con los objetivos específicos planteados para esta investigación. 
Tabla 2

Operacionalización objetivo específico 1: Determinar los mecanismos de coordinación empleados en el desarrollo del Programa de Innovaciones Educativas

Definición conceptual

Definición operacional
Son las formas mediante las cuales, se articula la división del trabajo, tales como la adaptación mutua (que requiere un sencillo proceso de comunicación informal), supervisión directa (donde una persona da órdenes a otros cuando un cierto número de personas deben trabajar juntas), la estandarización del proceso de trabajo (en este sentido, se debe programar el trabajo de distintas personas para coordinar de una forma rigurosa), la estandarización de los resultados (lo cual conduce a la especificación de resultados), la estandarización de las habilidades (en donde un trabajador aplica los conocimientos que tiene, en el trabajo que realiza, de modo que la coordinación se logra cuando cada trabajador sabe lo que se espera de él) y la estandarización de normas (lo cual significa que los trabajadores comparten una serie de creencias comunes y logran coordinarse a partir de este hecho). Estos mecanismos pueden considerarse como los elementos básicos de una estructura, pues mantienen la cohesión de las organizaciones. No obstante, algunas organizaciones prefieren un mecanismo más que otros, pero todas aplican (en mayor o menor grado), estos mecanismos (Mintzberg y Quinn, 1993).

Acciones de articulación aplicadas por parte del profesional en administración de la educación responsable de las organizaciones educativas con los miembros de la comunidad educativa (personal docente, administrativo, estudiantes y padres y madres de familia y organismos de apoyo) y autoridades competentes tales como el asesor nacional y director regional en relación a la ejecución del Programa Nacional de Innovaciones Educativas. Estas acciones de articulación se refieren a la capacidad de adaptación mutua de parte de los funcionarios, cohesión para trabajar en equipos, comunicación fluida, supervisión directa, asignación adecuada de responsabilidades, estandarización del proceso, programación explícita del trabajo, comunicación de los objetivos por alcanzar, idoneidad del profesional según funciones, estandarización de normas, se comparten conocimientos y habilidades con los miembros para el logro de los objetivos. 


\begin{tabular}{|c|c|c|c|c|c|}
\hline $\begin{array}{l}\text { Eje temático de la } \\
\text { categoría de análisis } \\
\text { (objetivo 1) }\end{array}$ & Indicadores & $\begin{array}{l}\text { Pregunta } \\
\text { entrevista al } \\
\text { director de } \\
\text { cada colegio }\end{array}$ & $\begin{array}{l}\text { Pregunta } \\
\text { entrevista al } \\
\text { responsable } \\
\text { del PNIE }\end{array}$ & $\begin{array}{l}\text { Pregunta } \\
\text { entrevista } \\
\text { al } \\
\text { supervisor }\end{array}$ & $\begin{array}{c}\text { Pregunta al } \\
\text { asesor de IE } \\
\text { asignado al } \\
\text { programa }\end{array}$ \\
\hline \multirow{2}{*}{$\begin{array}{l}\text { Adaptación mutua } \\
\text { de parte de los } \\
\text { funcionarios } \\
\text { involucrados }\end{array}$} & $\begin{array}{l}\text { - Cohesión adecuada } \\
\text { para trabajar en } \\
\text { equipos. }\end{array}$ & 2.2 & 2.2 & & 2.2 \\
\hline & $\begin{array}{l}\text { - Fluidez y dinamismo } \\
\text { en el desarrollo de la } \\
\text { comunicación entre el } \\
\text { director y el funcionario } \\
\text { responsable. }\end{array}$ & 2.3 a 2.4 & 2.3 & & 2.3 a 2.4 \\
\hline $\begin{array}{l}\text { Supervisión } \\
\text { directa entre los } \\
\text { involucrados }\end{array}$ & $\begin{array}{l}\text { - Asignación y } \\
\text { monitoreo de } \\
\text { responsabilidades en } \\
\text { forma precisa. }\end{array}$ & 2.5 & 2.4 & 2.2 & 2.5 \\
\hline $\begin{array}{l}\text { Estandarización del } \\
\text { proceso de trabajo }\end{array}$ & $\begin{array}{l}\text { - Programación explícita } \\
\text { del trabajo a realizar. }\end{array}$ & 2.6 & 2.5 & & 2.6 \\
\hline $\begin{array}{l}\text { Estandarización de } \\
\text { los resultados }\end{array}$ & $\begin{array}{l}\text { - Comunicación al } \\
\text { personal involucrado de } \\
\text { los resultados según los } \\
\text { objetivos por alcanzar } \\
\text { del Programa. }\end{array}$ & 2.7 & 2.6 & 2.3 & 2.7 \\
\hline \multirow[t]{2}{*}{$\begin{array}{l}\text { Estandarización de } \\
\text { las habilidades }\end{array}$} & $\begin{array}{l}\text { - Idoneidad en la } \\
\text { aplicación de los } \\
\text { conocimientos del } \\
\text { personal involucrado } \\
\text { en las tareas } \\
\text { asignadas. }\end{array}$ & 2.8 & 2.7.a & 2.4 & 2.8 \\
\hline & $\begin{array}{l}\text { - Claridad de parte del } \\
\text { funcionario sobre lo } \\
\text { que se espera de él. }\end{array}$ & 2.9 & 2.7.b & & 2.9 \\
\hline $\begin{array}{l}\text { Estandarización de } \\
\text { las normas }\end{array}$ & $\begin{array}{l}\text { - Los funcionarios } \\
\text { comparten sus } \\
\text { conocimientos y } \\
\text { habilidades con sus } \\
\text { compañeros, para lograr } \\
\text { los objetivos planeados. }\end{array}$ & 2.10 & 2.8 & & 2.10 \\
\hline
\end{tabular}

Instrumentalización

Entrevista al director, al funcionario responsable del Programa Nacional de Innovaciones (de cada centro educativo); al supervisor y al asesor asignado al Programa de Innovaciones.

Fuente: Elaboración propia, 2011. 
Tabla 3

Operacionalización objetivo específico 2: Describir la estructura de organizacióndel Programa Nacional de Innovaciones Educativas para su desarrollo en las tres instituciones seleccionadas

\begin{tabular}{|c|c|c|c|c|c|}
\hline Categoría de análisis & \multicolumn{5}{|c|}{ Estructura de organización } \\
\hline Definición conceptual & \multicolumn{5}{|c|}{$\begin{array}{l}\text { Consiste en un conjunto de puestos o de departamentos, que orienta la conducta } \\
\text { de individuos y grupos, para que se logren los objetivos y metas planteadas de la } \\
\text { organización (Ivancevich et al., 1997). }\end{array}$} \\
\hline $\begin{array}{l}\text { Definición } \\
\text { operacional }\end{array}$ & \multicolumn{5}{|c|}{$\begin{array}{l}\text { Es la forma a través de la cual, por medio de un organigrama, un manual descriptivo de } \\
\text { puestos, departamentos o comités, están estructurados o constituidos adecuadamente } \\
\text { en los centros educativos que utilizan el Programa Nacional de Innovaciones } \\
\text { Educativas, de modo que conlleve a canalizar adecuadamente, el comportamiento y/o } \\
\text { actitudes de los miembros de cada una de las instituciones de una forma coherente, } \\
\text { para lograr los fines u objetivos propuestos por la organización educativa. }\end{array}$} \\
\hline $\begin{array}{l}\text { Eje temático de la } \\
\text { categoría de análisis } \\
\text { (objetivo 2) }\end{array}$ & Indicador & $\begin{array}{l}\text { Pregunta } \\
\text { entrevista al } \\
\text { director de } \\
\text { cada colegio }\end{array}$ & $\begin{array}{l}\text { Pregunta } \\
\text { entrevista al } \\
\text { responsable } \\
\text { del PNIE }\end{array}$ & $\begin{array}{l}\text { Pregunta } \\
\text { entrevista } \\
\quad \text { al } \\
\text { supervisor }\end{array}$ & $\begin{array}{l}\text { Pregunta } \\
\text { entrevista al } \\
\text { Asesor } \\
\text { asignado al } \\
\text { programa }\end{array}$ \\
\hline \multirow{4}{*}{$\begin{array}{l}\text { Estructura según un } \\
\text { manual descriptivo } \\
\text { de puestos }\end{array}$} & $\begin{array}{l}\text { Cuenta el centro } \\
\text { educativo con }\end{array}$ & & & & \\
\hline & $\begin{array}{l}\text { - Existencia de un } \\
\text { manual descriptivo de } \\
\text { puestos que permita } \\
\text { la consecución de los } \\
\text { objetivos propuestos. }\end{array}$ & 3.1 & 3.1 & & 3.1 \\
\hline & $\begin{array}{l}\text { - Existencia de un } \\
\text { organigrama en } \\
\text { donde la comunidad } \\
\text { educativa visualice } \\
\text { la forma en la cual se } \\
\text { divide el trabajo en el } \\
\text { centro educativo. }\end{array}$ & 3.2 & 3.2 & 3.1 & 3.2 \\
\hline & $\begin{array}{l}\text { - Se visualiza en } \\
\text { forma clara dentro } \\
\text { del organigrama } \\
\text { institucional el } \\
\text { Programa. }\end{array}$ & 3.3 & 3.3 & 3.2 & 3.3 \\
\hline
\end{tabular}




\begin{tabular}{|c|c|c|c|c|c|}
\hline \multirow{3}{*}{$\begin{array}{l}\text { Estructura según la } \\
\text { departamentalización } \\
\text { o comités }\end{array}$} & $\begin{array}{l}\text { Está la institución } \\
\text { conformada por: }\end{array}$ & & & \multirow{3}{*}{3.3} & \multirow[b]{2}{*}{3.4} \\
\hline & $\begin{array}{l}\text { - Departamentalización } \\
\text { (por área académica). }\end{array}$ & 3.4 & 3.4 & & \\
\hline & $\begin{array}{l}\text { - Comités y/o puestos } \\
\text { de trabajo permitan } \\
\text { el desarrollo } \\
\text { adecuado del } \\
\text { programa. }\end{array}$ & 3.5 & 3.5 & & 3.5 \\
\hline Instrumentalización & $\begin{array}{l}\text { Entrevista al director, } \\
\text { Innovaciones (de cada c } \\
\text { de Innovaciones. }\end{array}$ & incio & bons & Prog & $\begin{array}{l}\text { ional de } \\
\text { Programa }\end{array}$ \\
\hline
\end{tabular}

Fuente: Elaboración propia, 2011.

Tabla 4

Operacionalización objetivo específico 3: Reconocer el proceso de planificación llevado a cabo para el desarrollo del Programa Nacional de Innovaciones Educativas

Consiste en seis etapas que implican acciones como evaluar las condiciones actuales (que puede ser basándose en los objetivos o tendencias; o recopilando información de la organización), determinar objetivos y metas (especificando las condiciones deseadas a futuro; o los estados o condiciones futuras que contribuyen al cumplimiento de

Definición la finalidad de la organización), establecer un plan de acción (o medios específicos conceptual prescritos para el logro de los objetivos; y también se debe contar con la previsión), asignar recursos (financieros, físicos, humanos, tiempo u otro de la organización), ejecución (lo cual se relaciona a la delegación de tareas, a la acción impulsada por los objetivos y con la obtención de datos para retroalimentación) y control (lo cual incluye todas las actividades de gestión que tienen por objeto definir si los resultados obtenidos corresponden a los propuestos) (Ivancevich et ál. 1997).

Conjunto de etapas o fases utilizadas por el profesional de la administración de la educación, en coordinación con los funcionarios, departamentos o comités respectivos de la institución

Definición operacional educativa que dirige; para implementar el Programa Nacional de Innovaciones Educativas. Tales etapas, conducen a estudiar las condiciones actuales de la organización, determinar objetivos o metas, establecimiento de un plan de acción, asignación de recursos, así como la ejecución y control; para aplicar el Programa en el centro educativo. 


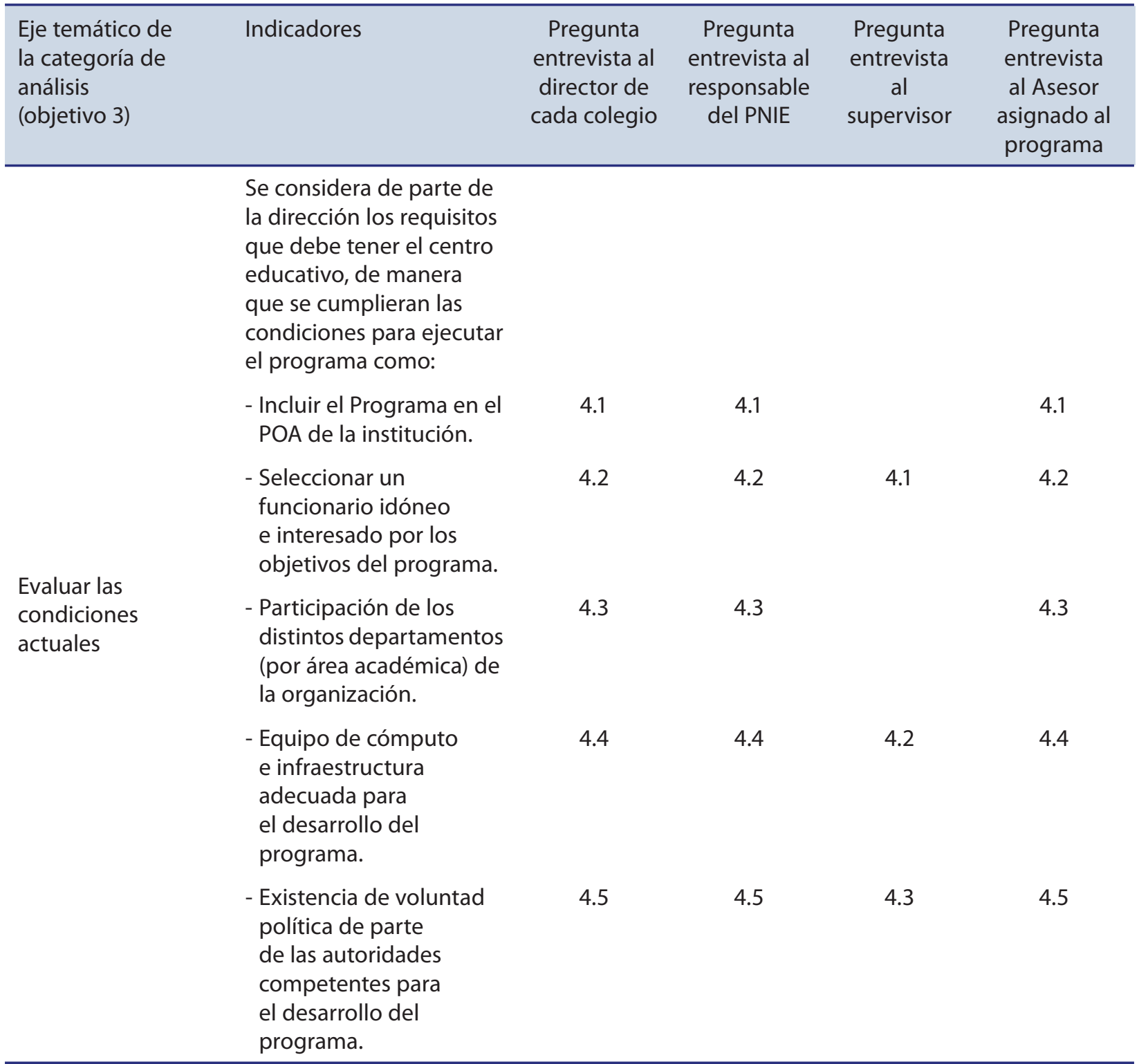




\begin{tabular}{|c|c|c|c|c|c|}
\hline \multirow{5}{*}{$\begin{array}{l}\text { Determinar los } \\
\text { objetivos y metas }\end{array}$} & $\begin{array}{l}\text { Se tomó en cuenta desde } \\
\text { la dirección: }\end{array}$ & & & & \\
\hline & $\begin{array}{l}\text { - los fines y objetivos } \\
\text { del programa, con la } \\
\text { filosofía institucional } \\
\text { (misión y visión). }\end{array}$ & 4.6 & 4.6 & & 4.6 \\
\hline & $\begin{array}{l}\text { - las directrices } \\
\text { propuestas por el MEP. }\end{array}$ & 4.7 & 4.7 & 4.4 & 4.7 \\
\hline & $\begin{array}{l}\text { - los objetivos propuestos } \\
\text { por el Programa, y } \\
\text { sus beneficios a la } \\
\text { organización educativa. }\end{array}$ & 4.8 & 4.8 & & 4.8 \\
\hline & $\begin{array}{l}\text { - los objetivos o } \\
\text { metas propuestos } \\
\text { por el programa } \\
\text { que contribuyeron } \\
\text { al cumplimiento de } \\
\text { la finalidad de la } \\
\text { organización, como un } \\
\text { todo. }\end{array}$ & 4.9 & 4.9 & 4.5 & 4.9 \\
\hline \multirow{3}{*}{$\begin{array}{l}\text { Establecimiento de } \\
\text { un plan de acción }\end{array}$} & $\begin{array}{l}\text { Dentro de un plan } \\
\text { de acción el director } \\
\text { considera: }\end{array}$ & & & & \\
\hline & $\begin{array}{l}\text { - Aplicación sistemática } \\
\text { de distintas acciones y/o } \\
\text { actividades para lograr } \\
\text { los objetivos. }\end{array}$ & 4.10 & 4.10 & 4.6 & 4.10 \\
\hline & $\begin{array}{l}\text { - Previsión ante cualquier } \\
\text { dificultad, producto } \\
\text { de la aplicación del } \\
\text { programa. }\end{array}$ & 4.11 & 4.11 & 4.7 & 4.11 \\
\hline
\end{tabular}




\begin{tabular}{|c|c|c|c|c|c|}
\hline \multirow{4}{*}{$\begin{array}{l}\text { Asignación de } \\
\text { recursos }\end{array}$} & \multicolumn{5}{|l|}{$\begin{array}{l}\text { El profesional de la } \\
\text { administración de la } \\
\text { educación toma en } \\
\text { cuenta: }\end{array}$} \\
\hline & $\begin{array}{l}\text { - las distintas formas a } \\
\text { través de las cuales se } \\
\text { puede proporcionar } \\
\text { al programa, los } \\
\text { requerimientos físicos } \\
\text { mínimos necesarios. }\end{array}$ & 4.12 & 4.12 & & 4.12 \\
\hline & $\begin{array}{l}\text { - la coordinación con la } \\
\text { autoridad competente } \\
\text { del MEP la asignación } \\
\text { del funcionario } \\
\text { idóneo que aplique el } \\
\text { programa. }\end{array}$ & 4.13 & 4.13 & & 4.13 \\
\hline & $\begin{array}{l}\text { - la selección y } \\
\text { motivación de la } \\
\text { capacitación del } \\
\text { funcionario responsable } \\
\text { en la institución. }\end{array}$ & 4.14 & 4.14 & 4.8 & 4.14 \\
\hline & $\begin{array}{l}\text { El director cuenta o } \\
\text { dispone para el desarrollo } \\
\text { de la innovación, la } \\
\text { delegación de distintas } \\
\text { tareas relacionadas con la } \\
\text { ejecución del Programa, } \\
\text { según: }\end{array}$ & & & & \\
\hline & $\begin{array}{c}\text { - los objetivos } \\
\text { propuestos. }\end{array}$ & 4.15 & 4.15 & 4.9 & 4.15 \\
\hline Ejecución & $\begin{array}{l}\text { - la información disponible } \\
\text { para fortalecer la } \\
\text { realimentación durante } \\
\text { el proceso, que } \\
\text { conduzca a mejorar } \\
\text { la implementación } \\
\text { del programa, entre } \\
\text { los miembros de la } \\
\text { organización educativa } \\
\text { (director y docentes, } \\
\text { docentes y estudiantes, } \\
\text { docentes). }\end{array}$ & 4.16 & 4.16 & 4.10 & 4.16 \\
\hline
\end{tabular}




\begin{tabular}{|c|c|c|c|c|c|}
\hline \multirow[b]{2}{*}{ Control } & $\begin{array}{l}\text { La dirección considera } \\
\text { para el monitoreo del } \\
\text { desarrollo del programa: }\end{array}$ & \multirow[b]{2}{*}{4.17} & \multirow[b]{2}{*}{4.17} & \multirow[b]{2}{*}{4.11} & \multirow[b]{2}{*}{4.17} \\
\hline & $\begin{array}{l}\text { - la realización de } \\
\text { acciones sistemáticas, } \\
\text { para definir si los } \\
\text { resultados obtenidos } \\
\text { de la aplicación del } \\
\text { Programa corresponden } \\
\text { a los propuestos } \\
\text { inicialmente. }\end{array}$ & & & & \\
\hline Instrumentalización & $\begin{array}{l}\text { Entrevista al director, } \\
\text { Innovaciones (de cada } \\
\text { Programa de Innovacion }\end{array}$ & $\begin{array}{l}\text { ncion } \\
\text { o ed }\end{array}$ & $\begin{array}{ll}\text { nsal } \\
\text { al si }\end{array}$ & $\begin{array}{l}\text { Progr } \\
\text { or y as }\end{array}$ & $\begin{array}{l}\text { ional de } \\
\text { gnado al }\end{array}$ \\
\hline
\end{tabular}

Fuente: Elaboración propia, 2011.

Tabla 5

Operacionalización objetivo específico 4: Describir los sistemas de control empleados en la gestión del Programa Nacional de Innovaciones Educativas

\begin{tabular}{ll}
\hline Categoría de análisis & \multicolumn{1}{c}{ Sistemas de control } \\
\hline Conceptualización & $\begin{array}{l}\text { Se basan en las medidas operativas, pues controlan las operaciones a través del } \\
\text { producto terminado, y permiten a los trabajadores evaluar los procesos a medida que } \\
\text { se desarrollan (Ivancevich, et ál. 1997). }\end{array}$ \\
$\begin{array}{l}\text { Definición } \\
\text { operacional }\end{array}$ & $\begin{array}{l}\text { Consiste en el conjunto de acciones sistemáticas empleadas por la administración } \\
\text { de cada una de las instituciones, con la finalidad de comprobar que el personal } \\
\text { participante está implementando, adecuadamente, el Programa de Innovaciones } \\
\text { Educativas, para garantizar la calidad educativa deseada a los estudiantes que tienen } \\
\text { bajo su responsabilidad. }\end{array}$
\end{tabular}




\begin{tabular}{|c|c|c|c|c|c|}
\hline $\begin{array}{l}\text { Ejes temáticos de la } \\
\text { categoría de análisis } \\
\text { (objetivo 4) }\end{array}$ & Indicadores & $\begin{array}{l}\text { Pregunta } \\
\text { entrevista al } \\
\text { director de } \\
\text { cada colegio }\end{array}$ & $\begin{array}{l}\text { Pregunta } \\
\text { entrevista al } \\
\text { responsable } \\
\text { del PNIE }\end{array}$ & $\begin{array}{l}\text { Pregunta } \\
\text { entrevista al } \\
\text { supervisor }\end{array}$ & $\begin{array}{l}\text { Pregunta } \\
\text { entrevista } \\
\text { al asesor } \\
\text { asignado al } \\
\text { programa }\end{array}$ \\
\hline
\end{tabular}

Desde la administración

se controla, por medio

de distintas acciones:

Evaluar procesos

durante la puesta en marcha
- la adecuada aplicación y cumplimiento de responsabilidades del funcionario.

- la asesoría respectiva del MEP, durante la implementación del programa.
5.1

5.1

5.1

5.1

5.2

5.2

5.2

5.2

\begin{tabular}{llllll}
\hline Producto terminado & $\begin{array}{l}\text { - porcentaje de } \\
\text { promoción alcanzado } \\
\text { por los estudiantes } \\
\text { que participan en el } \\
\text { Programa. }\end{array}$ & 5.3 & 5.3 & 5.3 & 5.3 \\
\hline
\end{tabular}

Instrumentalización

Entrevista al director, al funcionario responsable del Programa Nacional de Innovaciones (de cada centro educativo); al supervisor y asesor asignado al Programa de Innovaciones.

Fuente: Elaboración propia, 2011.

Tabla 6

Operacionalización objetivo específico 5: Describir las estrategias de evaluación implementadas en el desarrollo del Programa Nacional de Innovaciones Educativas

\begin{tabular}{|c|c|}
\hline Categoría de análisis & Estrategias de evaluación \\
\hline \multirow[t]{3}{*}{ Conceptualización } & $\begin{array}{l}\text { Las estrategias son un conjunto de medios a través de los que se alcanzan los objetivos a } \\
\text { largo plazo (David, 2008), lo cual es indispensable en el nivel organizacional, debido a que la } \\
\text { aplicación de acciones o medios, son la clave para determinar si se alcanzaron los objetivos o } \\
\text { metas. }\end{array}$ \\
\hline & $\begin{array}{l}\text { La evaluación constituye un momento más del ciclo de intervención social, a lo largo del } \\
\text { cual se realizan distintos tipos de evaluaciones que permiten juicios valorativos con aval } \\
\text { empírico (Fernández-Ballesteros, 2001); es decir, en una intervención social, es indispensable } \\
\text { la evaluación, como un proceso en el cual se interioriza un criterio basado en experiencias, } \\
\text { para emitir juicios de valor. }\end{array}$ \\
\hline & $\begin{array}{l}\text { Constituyen los medios, acciones o atributos para verificar si efectivamente, se cumplieron } \\
\text { los objetivos o metas propuestos, emitiendo un juicio valorativo durante y después de la } \\
\text { aplicación, en un ciclo de intervención social (David, 2008; Fernández-Ballesteros, 2001). }\end{array}$ \\
\hline
\end{tabular}




\begin{tabular}{|c|c|c|c|c|c|}
\hline $\begin{array}{l}\text { Definición } \\
\text { operacional }\end{array}$ & \multicolumn{5}{|c|}{$\begin{array}{l}\text { Acciones sistemáticas empleadas por la Administración de cada una de las tres } \\
\text { instituciones estudiadas, para comprobar si se cumplieron o no, los objetivos } \\
\text { planteados, durante y después de la aplicación del Programa Nacional de Innovaciones } \\
\text { Educativas, en la organización educativa. }\end{array}$} \\
\hline $\begin{array}{l}\text { Eje temático de la } \\
\text { categoría de análisis } \\
\text { (objetivo 5). }\end{array}$ & Indicador & $\begin{array}{l}\text { Pregunta } \\
\text { entrevista al } \\
\text { director de } \\
\text { cada colegio }\end{array}$ & $\begin{array}{l}\text { Pregunta } \\
\text { entrevista al } \\
\text { responsable } \\
\text { del PNIE. }\end{array}$ & $\begin{array}{l}\text { Pregunta } \\
\text { entrevista } \\
\quad \text { al } \\
\text { supervisor }\end{array}$ & $\begin{array}{l}\text { Pregunta } \\
\text { entrevista } \\
\text { al Asesor } \\
\text { asignado al } \\
\text { Programa }\end{array}$ \\
\hline \multirow{2}{*}{$\begin{array}{l}\text { Cumplimiento de } \\
\text { objetivos propuestos }\end{array}$} & $\begin{array}{l}\text { - Existencia de } \\
\text { un sistema de } \\
\text { evaluación especial } \\
\text { para el estudiante } \\
\text { que participa en el } \\
\text { programa. }\end{array}$ & 6.1 & 6.1 & & 6.1 \\
\hline & $\begin{array}{l}\text { - Valoración del } \\
\text { Informe que debe } \\
\text { brindar el funcionario } \\
\text { que participe en el } \\
\text { Programa. }\end{array}$ & 6.2 & 6.2 & 6.1 & 6.2 \\
\hline $\begin{array}{l}\text { Adquisición de la } \\
\text { calidad educativa. }\end{array}$ & $\begin{array}{l}\text { - Obtención de } \\
\text { resultados deseados } \\
\text { en el centro educativo } \\
\text { con la aplicación del } \\
\text { Programa, al finalizar } \\
\text { el curso lectivo. }\end{array}$ & 6.3 & 6.3 & 6.2 & 6.3 \\
\hline Instrumentalización & \multicolumn{5}{|c|}{$\begin{array}{l}\text { Entrevista al director, al funcionario responsable del Programa Nacional de } \\
\text { Innovaciones (de cada centro educativo); al supervisor y asesor asignado al Programa } \\
\text { de Innovaciones. }\end{array}$} \\
\hline
\end{tabular}

Fuente: Elaboración propia, 2011.

\section{Técnicas e instrumentos de recopilación de información}

Como técnica e instrumento se utilizó la entrevista; de modo que se garantiza confiabilidad y validez con el análisis de los resultados obtenidos. La entrevista, se aplicó al profesional en administración de la educación de cada centro educativo, al funcionario responsable a través de quien se canaliza el Programa Nacional de Innovaciones Educativas; al supervisor y al asesor nacional de informática asignado al programa; de modo que se caracteriza una profunda interacción con los sujetos, para la recopilación de información pertinente. 


\section{Sistematización y análisis de resultados}

Se expone a continuación, el análisis del indicador más importante (por categoría de análisis), de los datos recopilados para efectos de la investigación, en la cual se estudia la gestión de las organizaciones educativas respecto de la implementación del Programa Nacional de Innovaciones Educativas, en tres instituciones educativas de secundaria, del sistema educativo público costarricense, pertenecientes al circuito 09 de la Dirección Regional de Educación San José Norte, en Moravia, Costa Rica. El trabajo de campo se desarrolló durante el II semestre de 2011.

Este análisis se sustenta en la información recopilada de las entrevistas dirigidas a los profesionales de la administración de la educación, el funcionario responsable o representante del Programa Nacional de Innovaciones Educativas en el centro educativo, al Supervisor del circuito, y al Asesor Nacional asignado al Programa, así como con la fundamentación teórica de las categorías de análisis que enmarcaron este estudio.

Considerando los objetivos planteados, se desarrollaron cinco tópicos: determinación de los mecanismos de coordinación empleados en el desarrollo del programa; conocer la estructura de organización del programa; reconocimiento del proceso de planificación llevado a cabo para el desarrollo del programa; conocer los sistemas de control empleados en la gestión del programa; y finalmente, la descripción de las estrategias de evaluación implementadas en el desarrollo del Programa Nacional de Innovaciones Educativas.

Básicamente, se analizó desde la gestión de la educación la forma en que el profesional de la administración de la educación aplica el Programa Nacional de Innovaciones Educativas; respecto de las categorías de análisis que se plasman en los objetivos específicos planteados.

\section{Caracterización de las instituciones objeto de estudio}

Las instituciones participantes en este estudio, se localizan en el cantón de Moravia; dos de ellas, se caracterizan por atender estudiantes de clase media-baja, y baja, el otro, atiende alumnos de clase media en adelante. Para efectos de este análisis, a las instituciones participantes en este estudio, se les asignó la siguiente nomenclatura:

- Liceo Bilingüe de la Trinidad de Moravia: Colegio 1

- Liceo Abelardo Bonilla: Colegio 2

- Liceo Laboratorio-UCR-Emma Gamboa: Colegio 3

Uno de los directores posee el grado académico de doctorado, mientras que los otros dos tienen el grado académico de maestría y licenciatura. 
En el colegio 1, el funcionario responsable de coordinar el Programa Nacional de Innovaciones Educativas, es un analista, cuyo último grado académico, es el bachillerato universitario.

En el colegio 2, el Programa de Innovaciones se canaliza a través de una responsabilidad compartida entre un analista y un docente de innovación; de los cuales, para este estudio, se seleccionó al analista, quien tiene como grado académico, el bachillerato universitario.

En el tercer centro educativo, el responsable es un docente de informática educativa, cuyo último grado académico fue Maestría en informática educativa. No hay analista.

Los tres centros educativos, tienen una dirección tipo D2, que corresponde a una clasificación del Ministerio de Educación Pública, de acuerdo con el número de estudiantes; y además, son académicos públicos diurnos. La cantidad de personas de cada centro educativo, se contemplan en la siguiente tabla:

Tabla 7

Cantidad de estudiantes y profesores de los tres centros educativos

\begin{tabular}{|c|c|c|c|}
\hline Institución & $\begin{array}{l}\text { Liceo Bilingüe de la } \\
\text { Trinidad de Moravia }\end{array}$ & Liceo Abelardo Bonilla & $\begin{array}{c}\text { Liceo Laboratorio UCR- } \\
\text { Emma Gamboa }\end{array}$ \\
\hline Número de profesores & 50 & 34 & 42 \\
\hline Número de estudiantes & 632 & 590 & 500 \\
\hline
\end{tabular}

Fuente: Profesionales de la administración de la educación de las instituciones participantes del estudio, 2011.

Respecto de las categorías de análisis que se plasman en los objetivos específicos planteados, se expone el análisis del indicador más importante (por categoría) a continuación.

\section{Categoría de análisis: mecanismos de coordinación que se utilizaron en el desarrollo del Programa de Innovaciones}

Los mecanismos de coordinación son importantes para el profesional de la administración de la educación, debido a que describen y determinan el uso y la forma en la cual, en este caso la adaptación mutua, son empleados en una organización educativa, en el desarrollo del Programa Nacional de Innovaciones Educativas; ya que, tal y como lo manifiesta Mintzberg y Quinn (1993), son los elementos básicos de una estructura, articulando la división del trabajo y manteniendo la cohesión de la organización. 
De este modo, si desde la administración de la educación se combinan adecuadamente, hacen posible que un grupo de personas de un centro educativo, trabajen juntas para desarrollar el Programa Nacional de Innovaciones Educativas; y con ello, el software libre.

\section{El eje temático: adaptación mutua}

Indicador: Fluidez y dinamismo en el desarrollo de la comunicación entre el director y el funcionario responsable.

Respecto de la fluidez y dinamismo en el desarrollo de la comunicación, es un factor sumamente relevante en este estudio, considerar que para utilizar o aplicar la adaptación mutua, se requiere, según Mintzberg y Quinn (1993), de un proceso sencillo de comunicación, que no sea formal.

Por esta razón, es importante subrayar que en uno de los colegios, uno de los sujetos expresa que cuando requiere aplicar algún proyecto: “(...) lo presento por escrito, asesorando al director y proponiéndole pautas a seguir". En este sentido, parece que la adaptación mutua, no se está implementando adecuadamente, constituyendo esta, según Mintzberg y Quinn (1993), uno de los mecanismos de coordinación, con la finalidad de articular la división del trabajo.

En virtud de lo anterior, es claro que no hay una coordinación coherente entre el profesional de la administración de la educación y el funcionario responsable del programa; lo cual sesga el adecuado desarrollo de este.

Sin embargo, respecto del colegio 1, lo que el profesional en administración de la educación manifiesta, es el uso de una base de datos, así como circulares. También, se estudia la posibilidad del uso del correo electrónico. Por su parte, el analista manifestó que hay comunicación, pero con los compañeros; con el director parece que lo que se ha tratado de impulsar son los proyectos por medio de talleres de innovación.

Por eso, parece que no hay un buen canal de comunicación entre el analista y el director, que permita desarrollar los talleres y/o otros tópicos del programa adecuadamente. Parece que no se manifiesta lo que Mintzberg y Quinn (1993) llama un proceso sencillo de comunicación informal.

En los otros dos centros educativos, sí se genera un canal de comunicación; en el colegio 2 se comunicó la incorporación del programa al centro educativo, por medio de un consejo de profesores, entregándoles simultáneamente documentación relacionada; además, el encargado del programa fue un gran apoyo en este proceso. El analista expresó la flexibilidad respecto de la comunicación que fomenta la administración del centro educativo, pues manifiesta apertura y disponibilidad, en relación con el Programa de Innovación. 
Esto es importante para que el programa funcione, pues inicialmente, entre el funcionario responsable y el profesional de la administración de la educación, sin perder autoridad; se manifiesta una comunicación sencilla y a la vez informal, que se transmite paulatinamente, al resto de docentes del centro educativo.

En el tercer centro educativo, inicialmente el profesional de la administración de la educación asistió a una capacitación; luego, se desarrolló un taller en el centro educativo, donde el asesor asignado al programa, explicó todo lo asociado al mismo. Posteriormente, la dirección en conjunto con la persona responsable, desarrollan el programa. Ante esto, el funcionario responsable expresa la disponibilidad de la directora de ofrecer libertad, apertura y mucha comunicación. En este caso en particular, se manifiesta un canal de comunicación fluido, dinámico y a la vez responsable.

Se observa claramente, que en los dos últimos centros educativos, hay dinamismo y comunicación entre el responsable del programa y el director o directora, lo cual se fortaleció, aún más, con la iniciativa desde la asesoría encargada del programa. Desde la asesoría, se creó un Foro Técnico (el cual es un espacio para la socialización de dudas técnicas, pedagógicas y administrativas; pues el programa es grande y tiene pocos funcionarios); en el cual es evidente la comunicación dinámica y fluida con la cual se maneja la información (en la gran mayoría, dudas), que atañe a distintos tópicos relacionados al adecuado funcionamiento del programa.

Por las consideraciones anteriores, la adaptación mutua constituye un mecanismo que no es lo suficiente explotado por uno de los centros educativos estudiados, lo cual provoca, que ante la implementación del Programa de Innovaciones educativas, no se planteen objetivos claros, lo cual es sumamente fundamental, pues sesga una de las metas de la Administración de la educación, tal y como lo manifiesta Chiavenato (2000) al puntualizar: "En cualquier tipo de organización humana se busca el logro de determinados objetivos con eficiencia y eficacia. La administración dirige el esfuerzo de los grupos organizados" (p. 16).

No obstante, como se observará más adelante, de los seis mecanismos existentes para articular el trabajo (la adaptación mutua, la supervisión directa entre los involucrados, la estandarización del proceso de trabajo, la estandarización de los resultados, la estandarización de las habilidades, y la estandarización de normas), algunas organizaciones prefieren uno más que otros, pero todas aplican (en mayor o menor grado) estos mecanismos (Mintzberg y Quinn, 1993). En este aspecto, parece que la adaptación mutua es más explotada por otro de los centros educativos, pues uno de los sujetos expresó: "(...) La directora proporciona disponibilidad..., se manifiesta mucha comunicación con la directora; y ha facilitado materiales necesarios para trabajar, espacios en los consejos para la divulgación del programa".

De lo anterior, es evidente que la comunicación constituye una herramienta fundamental, que bien utilizada desde la administración de la educación, constituye una estrategia para 
coordinar adecuadamente, el funcionamiento del Programa Nacional de Innovaciones, tal y como lo manifiesta Chiavenato (2000): "(...) armoniza las actividades de una empresa para facilitar el trabajo y los resultados. Sincroniza recursos y actividades en proporciones adecuadas y ajusta los medios a los fines" (p. 92).

Por otra parte, el foro técnico permite conocer (no físicamente), tanto a cada uno de los responsables, como el contexto de los colegios participantes; lo cual es una cultura típica de aquellas personas que, por su naturaleza, apoyan el software libre, tal y como se muestra en la siguiente figura:

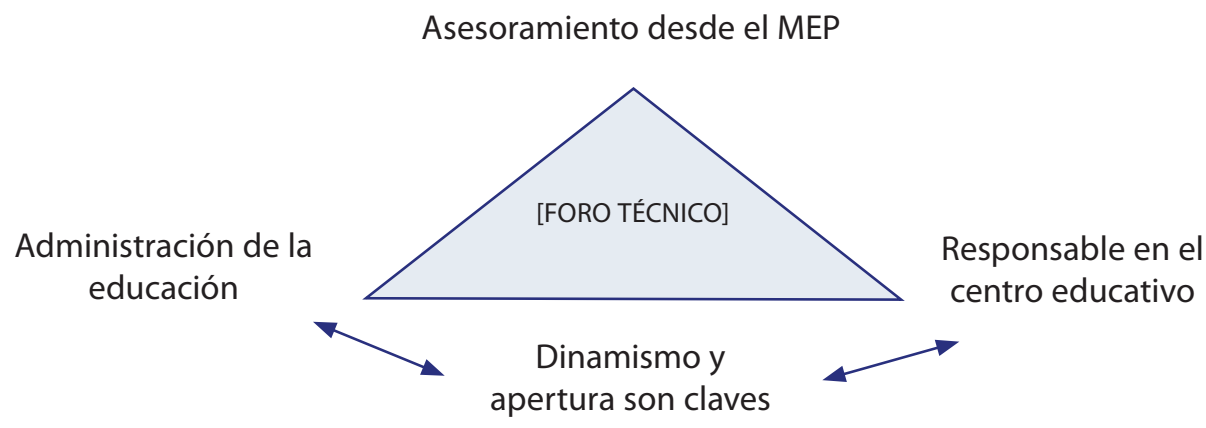

Figura 1. El foro técnico y la comunicación.

Fuente: Elaboración propia, 2011.

Es evidente cómo el Foro Técnico constituye un medio electrónico, dinámico y fluido, que agiliza el proceso de gestión para el profesional de la administración de la educación, respecto del desarrollo del programa. Sin embargo, la disponibilidad, la apertura, y los canales de comunicación informales, entre la administración de la educación y el responsable del programa en el centro educativo; son indispensables, para que el Programa de Innovación se desarrolle de la mejor forma posible.

En las siguientes tablas, se plasma un extracto de la información recopilada sobre la forma en la que se manifiesta la fluidez y dinamismo, en el desarrollo de la comunicación entre el profesional de la administración de la educación, el funcionario responsable del programa nacional de innovaciones de los tres centros educativos de este estudio; así como el asesor asignado al programa. 
Tabla 8

Fluidez y dinamismo, en el desarrollo entre el profesional de la administración de la educación, y el funcionario responsable del Programa Nacional de Innovaciones

\begin{tabular}{|c|c|c|}
\hline Institución & Director & Funcionario responsable \\
\hline Colegio 1 & $\begin{array}{l}\text { - El programa ya se estaba implementando } \\
\text { cuando llegué. } \\
\text { - Hay una base de datos para cuestiones } \\
\text { administrativas. } \\
\text { - También se usan las circulares, solicito y doy } \\
\text { indicaciones al personal. } \\
\text { - Sin embargo, falta mucho, falta equipo y } \\
\text { medios. } \\
\text { - La red inalámbrica está propensa a ser } \\
\text { hackeada. } \\
\text { - Se estudia la posibilidad de emplear el } \\
\text { correo electrónico, como un medio para } \\
\text { comunicarse, a pesar de que es posible } \\
\text { usarlo los fines de semana, sería un abuso, } \\
\text { pues no está en el horario de trabajo del } \\
\text { docente cumplir con una solicitud realizada } \\
\text { un sábado o domingo. Se trata de usarlo, } \\
\text { sin abusar, para tener eficiencia y eficacia. }\end{array}$ & $\begin{array}{l}\text { Si quiere implementar un proyecto, lo } \\
\text { presenta por escrito, asesorando al director y } \\
\text { proponiéndole pautas a seguir. } \\
\text { Hay comunicación con los docentes y les da } \\
\text { algunas pautas (cuidados, la responsabilidad } \\
\text { sobre el equipo). }\end{array}$ \\
\hline Colegio 2 & $\begin{array}{l}\text { - Por medio del coordinador de innovación } \\
\text { educativa, además, en consejo de } \\
\text { profesores se les comunicó en general, } \\
\text { luego se les entregó documentos. } \\
\text { - Se les invita a participar, ya sea a través de } \\
\text { reuniones, o de una manera informal. }\end{array}$ & $\begin{array}{l}\text { Hay mucha flexibilidad respecto de la } \\
\text { comunicación, pues el director sabe } \\
\text { escuchar. Tiene mucho tiempo de estar en la } \\
\text { institución. }\end{array}$ \\
\hline Colegio 3 & $\begin{array}{l}\text { - Inicialmente, se asistió a una capacitación, } \\
\text { luego, en el centro educativo se organizó } \\
\text { un taller, en donde el responsable del } \\
\text { programa del MEP, explicó todo lo } \\
\text { relacionado al programa. } \\
\text { - Posteriormente, cada docente coordina } \\
\text { con el responsable, de modo que se } \\
\text { generan herramientas de apoyo didáctico y } \\
\text { curricular. }\end{array}$ & $\begin{array}{l}\text { La directora proporciona disponibilidad, } \\
\text { de ofrecer libertad según la institución, } \\
\text { se manifiesta mucha comunicación con } \\
\text { la directora; y ha facilitado materiales } \\
\text { necesarios para trabajar, espacios en los } \\
\text { consejos para la divulgación del programa. }\end{array}$ \\
\hline
\end{tabular}

Fuente: Instrumento aplicado a los profesionales de la Administración de la Educación y funcionarios responsables del Programa de Innovaciones, 2011. 
Tabla 9

Fluidez y dinamismo, manifestados desde la asesoría del Programa Nacional de Innovaciones Educativas

Profesional

El programa se desarrolla por directriz superior. Se inicia con la entrega del equipo, para que
pueda ingresar en el programa, formalizándose el ingreso del colegio, sobre todo a nivel
presupuestario.
Respecto de GNU/Linux, el proyecto comenzó con la instalación de Linux en 600
computadoras, y a la vez, se firmó un contrato de aceptación de pilotaje, para que fuese
respetado, y no se manifestara el pirateo de software, lo cual fue iniciativa desarrollada por
primera vez a nivel de Centroamericano.
Además, el programa es grande, y tiene pocos funcionarios. Nació la idea del Foro Técnico,
considerando que muchos funcionarios eran nombrados en colegios muy lejanos; así que
se recopilaron los correos electrónicos de los funcionarios responsables. El Foro técnico es
un espacio para la socialización de dudas técnicas, pedagógicas y administrativas. Permite
conocer cómo trabajan otros, y genera identidad, personalismo; pero genera mucho trabajo.
Lamentablemente, en algunos colegios hay roces, conflictos. Una vez que el funcionario
Ilega al colegio, se conforma el comité de innovación, en coordinación con el director (por lo
general, el comité está formado por el director, funcionario, tres o cuatro profesores).

Fuente: Instrumento aplicado al asesor nacional asignado al Programa de Innovaciones, 2011.

\section{Categoría de análisis: estructura de organización del Programa de Innovaciones, para desarrollarlo en las tres instituciones}

La estructura de organización es una categoría de análisis importante, tanto para cada uno de los centros educativos, como también para el programa en estudio, debido a que es una de las formas a través de la cuales se articula el trabajo de una organización.

Varios autores coinciden al señalar que la estructura de la organización es el conjunto de puestos o de departamentos que orienta la conducta de individuos y grupos, para que se logren los objetivos y metas planteadas de la organización (Ivancevich et al., 1997).

Por eso en un centro educativo, es necesario que la administración de la educación elabore o plasme en un manual descriptivo de puestos, la forma en la cual se desarrollará el trabajo asociado a la aplicación del Programa Nacional de Innovaciones Educativas. 


\section{Eje temático: Estructura según la departamentalización o comités}

Indicador: Comités y/o puestos de trabajo que permitan el desarrollo adecuado del programa

Debido a la naturaleza del Programa de Innovaciones, es importante subrayar que desde la asesoría, se toma en cuenta la creación de un Comité de Innovación Institucional, uno de los componentes del programa, en el centro educativo. Esto es importante, pues por medio de este comité se canalizan muchos tópicos característicos del programa (como la innovación), que repercuten en la organización educativa.

Llama la atención para este estudio que uno de los profesionales de la Administración de la Educación manifiesta cierto cuidado al seleccionar al comité, debido a que expresó: "En el comité deben estar personas acreditadas, que sepan explicar, que tengan un manejo solvente de paquetes informáticos; para que el programa sea un apoyo curricular, ya que al usar software libre, permite que cada área académica mejore, pues es diferente, es innovador, no es la clásica tortuguita (...)". Es evidente, que se manifiesta una tendencia a seleccionar al personal que conforma el comité de innovación con sumo cuidado, para garantizar la adecuada implementación del Programa de Innovaciones en el centro educativo, como apoyo curricular; de modo que desde la Administración de la Educación, se trata de estimular, mediante una adecuada articulación y coordinación con el comité, la creatividad y la innovación, tal y como lo expresa Rodríguez (1999) cuando manifiesta:

En consonancia con esto y, en armonía con la idea de Vygotski con educación para el desarrollo, Piaget sostuvo que la educación debe orientarse a proveer el ambiente y los medios para nutrir la curiosidad epistémica del sujeto y la actividad exploratoria que llevaran a un aprendizaje significativo. (p.482)

Además, el comité de innovación se encarga de velar porque se cumpla el proceso de innovación institucional, mediante el uso adecuado de la tecnología y su aplicación en los procesos educativos (MEP, 2006). Sin embargo, en el colegio 1, se percibe como una entidad fiscalizadora, a la cual se le debe entregar un informe sobre aspectos presupuestarios o de inventario; lo cual es importante; pero en los otros dos centros educativos, el comité se visualiza, como un ente motivador tanto del desarrollo de la innovación y de la creatividad como del uso del software libre. Por eso, en los otros dos centros educativos, el director y el funcionario responsable consideran conjuntamente, con cautela, las personas que integrarán el comité, pues es uno de los entes del programa que, por su naturaleza, impulsarán la innovación y la creatividad. 
En referencia a lo anterior, es prioritario considerar que tanto la educación como el software libre, se plasman en el intercambio de conocimientos, produciendo nuevos saberes (Cobo, 2009); según la siguiente figura:

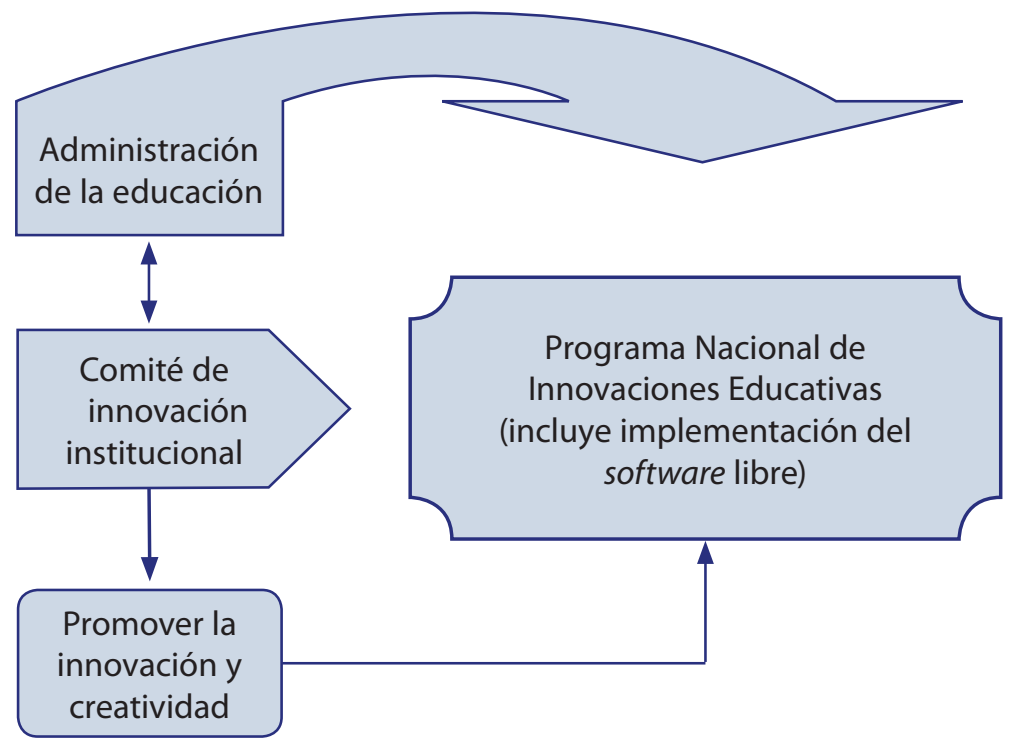

Figura 2. Comités y/o puestos de trabajo que permiten el desarrollo del Programa.

Fuente: Elaboración propia, 2011.

De la figura anterior, se infiere que es imprescindible estudiar a cabalidad, las competencias de cada uno de los integrantes del comité, para fomentar la innovación y la creatividad, a través del software libre, lo cual es impulsado desde el documento que se entrega a las instituciones, una vez que forman parte del programa, y en el cual, se manifiesta la apertura de todos los integrantes del comité, tal y como se extrae de la información obtenida durante el trabajo de campo: 
Tabla 10

Comités y/o puestos de trabajo que permitan el desarrollo adecuado del Programa de Innovaciones

\begin{tabular}{|c|c|c|}
\hline Institución & Dirección & Funcionario responsable \\
\hline \multirow[t]{2}{*}{ Colegio1 } & \multirow[t]{2}{*}{$\begin{array}{l}\text { Hay un comité, pero para desarrollar muchos } \\
\text { aspectos, se depende de la iniciativa del } \\
\text { profesor, lo que se impulsará el próximo año. }\end{array}$} & $\begin{array}{l}\text { El comité se reúne y señala, entre otros, la } \\
\text { necesidad de la sala de innovación y por lo } \\
\text { tanto, de espacio. }\end{array}$ \\
\hline & & $\begin{array}{l}\text { Falta el docente de innovación (según la } \\
\text { directriz del programa). }\end{array}$ \\
\hline Colegio 2 & $\begin{array}{l}\text { Criticidad, creatividad, deseos de superación, } \\
\text { iniciativa, entre otros. }\end{array}$ & $\begin{array}{l}\text { Hay un comité formado por un analista } \\
\text { (impulso el uso de Linux), el profesor de } \\
\text { informática, varios docentes y } 3 \text { estudiantes. } \\
\text { Pero hay mayor interacción entre el director, } \\
\text { el analista y el docente de informática para } \\
\text { estudiar las competencias y motivación de la } \\
\text { gente }\end{array}$ \\
\hline & $\begin{array}{l}\text { En el comité deben estar personas acreditadas, } \\
\text { que sepan explicar, que tengan un manejo } \\
\text { solvente de paquetes informáticos. }\end{array}$ & $\begin{array}{l}\text { La directora ha sido muy abierta, al formar el } \\
\text { comité, de modo que lo más importante, es } \\
\text { que el recurso sea utilizado, de modo que sea } \\
\text { un obietivo innovador }\end{array}$ \\
\hline Colegio 3 & $\begin{array}{l}\text { Así, el programa constituye un apoyo } \\
\text { curricular, ya que al usar software libre, } \\
\text { permite que cada área académica mejore, } \\
\text { pues es diferente, es innovador, no es la } \\
\text { clásica tortuguita. }\end{array}$ & \\
\hline
\end{tabular}

Fuente: Instrumento aplicado a los profesionales de la Administración de la Educación y funcionarios responsables del Programa de Innovaciones, 2011.

Tabla 11

Comités y/o puestos de trabajo que permitan el desarrollo adecuado del Programa de Innovación, propuesto desde la asesoría respectiva

Profesional

Se toma en cuenta lo que dice el Acuerdo de traslado, está normado. Sin embargo, se mantiene

Asesor la apertura,
el programa.

Fuente: Instrumento aplicado al asesor nacional asignado al Programa de Innovaciones, 2011. 


\section{Categoría de análisis: proceso de planificación llevado a cabo para desarrollar el Programa de Innovaciones Educativas}

Esta categoría de análisis es imprescindible tanto para la organización educativa como para el programa, pues a través del proceso de planificación, la administración de la educación puede establecer bajo qué circunstancias opera la organización, como conjunto. Desde esta perspectiva, Ivancevich et al. (1997) expresa que el proceso de planificación consta de varias etapas como la evaluación de las condiciones, determinación de los objetivos y metas, establecimiento de un plan de acción, asignación de recursos, ejecución y control.

A continuación, se expone el análisis de dos de los indicadores más importantes, asociados a esta categoría de análisis.

\section{Eje temático: Determinar los objetivos y metas}

Indicador: las directrices propuestas por el MEP

Respecto de las directrices propuestas por el MEP, es importante considerar que desde el momento en que un centro educativo se incorpora al programa, recibe a su vez, la documentación respectiva, y el programa queda bajo la administración del director del centro educativo. Por eso, en el marco de las distintas pautas por seguir, es interesante el aporte de Whitaker (1998), cuando señala la importancia de promover un proceso de gestión que impulse el compromiso, la comunicación, las interacciones, la iniciativa y las respuestas a los desafíos.

Sin embargo, por el momento, en uno de los centros educativos, se cumple en poco porcentaje, tal y como lo expresó el director: "Inicié labores hace poco tiempo, y he visto que se cumplen las directrices, en un estimado, cerca del 25\%". Es evidente que desde la administración de la educación, se está en una etapa de valoración general. En este aspecto, se requiere lo que Chiavenato (2000) llama una relación de causa-efecto entre dos fenómenos.

En los otros dos centros educativos se manifiesta seguimiento en relación con las directrices, pues hay reuniones periódicas tanto a nivel del comité de innovación, como entre el responsable del programa y el director, de modo que se manifiestan distintas necesidades respecto del equipo, infraestructura y afines. Tales directrices, procuran que el programa se desarrolle, de una forma pautada y a la vez flexible. Esto, lo puede articular el profesional de la administración de la educación, combinando tanto la autoridad que representa, como la responsabilidad que esto implica, lo cual se incentiva, acertadamente, desde la supervisión respectiva. 
Ante esta situación es importante aplicar, según las características del centro educativo, los mecanismos de coordinación adecuados con el fin de mantener la cohesión de las organizaciones (Mintzberg y Quinn, 1993).

En virtud de lo anterior, es interesante la forma en cual se procura articular distintas acciones para regular algunas directrices del MEP, tal y como lo manifestó uno de los directores entrevistados: "Hay sistemas de información con los cuales se agiliza tanto la divulgación como las normas a seguir, tales como los boletines y los espacios en los consejos de profesores. Hay controles".

Puntualizando, es evidente que desde la administración de la educación, es posible desarrollar un rol en el que se manifieste la regulación y el seguimiento de la adecuada implementación del Programa de Innovaciones educativas, lo cual manifiesta el supervisor, al expresar la importancia del ejercicio de la autoridad con responsabilidad. Lo anterior se esquematiza en la siguiente figura:

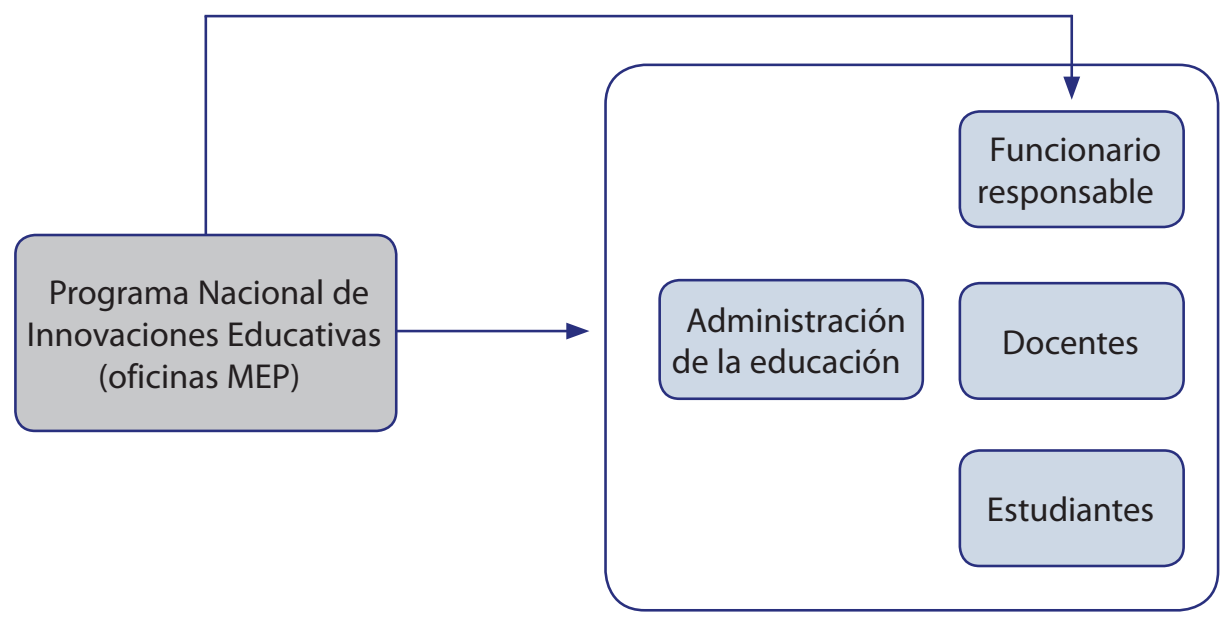

Figura 3. Directrices propuestas por el MEP.

Fuente: Elaboración propia, 2011.

En la figura anterior, se sintetiza la forma en la cual fluyen distintas directrices desde el MEP, ya sea al profesional en administración de la educación o al funcionario responsable del programa en el centro educativo, y de ahí, pasan al resto de la organización educativa.

Respecto de lo anterior, se extrajo lo siguiente, del trabajo de campo realizado: 
Tabla 12

Directrices propuestas por el MEP, en los tres centros educativos

\begin{tabular}{|c|c|c|}
\hline Institución & Dirección & Funcionario responsable \\
\hline Colegio 1 & $\begin{array}{l}\text { Inicié labores hace poco tiempo, y he visto que se } \\
\text { cumplen las directrices, en un estimado, cerca del } 25 \% \text {. }\end{array}$ & $\begin{array}{l}\text { Las directrices van dirigidas a los } \\
\text { docentes }\end{array}$ \\
\hline Colegio 2 & $\begin{array}{l}\text { Verificación en reuniones periódicas con el comité de } \\
\text { innovación institucional. Luego, se comunican al resto } \\
\text { del personal. }\end{array}$ & $\begin{array}{l}\text { Hay directrices, pero las propuestas } \\
\text { para la infraestructura casi no se } \\
\text { desarrolla. }\end{array}$ \\
\hline Colegio 3 & $\begin{array}{l}\text { Hay sistemas de información con los que se agiliza } \\
\text { tanto la divulgación como las normas a seguir, tales } \\
\text { como los boletines y los espacios en los consejos de } \\
\text { profesores. Hay controles. }\end{array}$ & $\begin{array}{l}\text { Se elaboran informes para la } \\
\text { directora, y si hay talleres, se } \\
\text { elaboran y se mandan al MEP. }\end{array}$ \\
\hline
\end{tabular}

Fuente: Instrumento aplicado a los profesionales de la Administración de la Educación y funcionarios responsables del Programa de Innovaciones, 2011.

Tabla 13

Directrices propuestas por el MEP, desde la asesoría respectiva y según supervisor

\begin{tabular}{ll}
\hline Profesional & \multicolumn{1}{c}{ Opinión expresada } \\
\hline Asesor & $\begin{array}{l}\text { El programa se le hace llegar al director, y él es el encargado de que se cumpla. Las } \\
\text { responsabilidades de la institución con el programa se reflejan en los informes anuales. }\end{array}$ \\
& $\begin{array}{l}\text { Eso le corresponde al director (desde el MEP se impulsa en los directores el ejercicio de Autoridad } \\
\text { con responsabilidad). }\end{array}$ \\
& Existen áreas de competencia.
\end{tabular}

Fuente: Instrumento aplicado al asesor nacional asignado al Programa Nacional de Innovaciones, y al supervisor del circuito 09, de la dirección regional de educación San José Norte, Moravia, 2011.

\section{Eje temático: Determinar los objetivos y metas}

Indicador: Los objetivos o metas propuestos por el programa que contribuyeron al cumplimiento de la finalidad de la organización, como un todo.

Los objetivos y las metas de una organización constituyen una de las pautas de una organización educativa, como se apuntó en el indicador anterior. Sin embargo, se debe considerar la organización como un todo, de modo que se tomen en cuenta los recursos de los cuales se dispone, para alcanzar los fines y objetivos planteados, por eso es importante la observación de Chiavenato (2009), cuando manifiesta: 
La administración es la herramienta específica que permite que las organizaciones sean capaces de generar resultados y de satisfacer necesidades. La organización existe dentro de la sociedad para producir resultados en ella y, sobre todo, para modificarla. De ahí la importancia del papel del administrador. (p.60)

En el colegio 1, el profesional de la administración de la educación manifestó: "Quedará para el 2012, establecerlo como un eje transversal". Es decir, desde la administración de la educación, sí hay una proyección de implementar el Programa de Innovaciones, pero transversalmente en la organización, de modo que de momento, solo se estudia esa opción, lo cual evidencia, que existe la posibilidad de obtener resultados, en función de un objetivo. Aunado a lo anterior, la persona responsable expresó: "Brindo colaboración, pero me saturan. Proveo el equipo, pero en las mejores condiciones posibles, colaborando con el recurso tecnológico".

Es decir, se manifiesta una saturación de trabajo, pero es evidente que se cumple con lo esperado, de modo que se colabore con el resto de integrantes de la organización; lo cual es importante, pues significa una iniciativa para alcanzar los objetivos planteados. En esta línea es oportuna la observación de David (2008), cuando manifiesta que las estrategias constituyen los medios a través de los que se obtienen objetivos.

Respecto de lo anterior, es importante señalar que si bien el Programa de Innovaciones es un componente transversal, paulatinamente ha contribuido, en dos de los tres centros educativos objeto de este estudio, a impulsar, casi simultáneamente, tanto el desarrollo de conocimiento, como otros aspectos propios de la vida de una organización; por ejemplo, la articulación y el cambio que se genera, así como el dinamismo y la apertura; pues en uno de los centros educativos objeto de este estudio, el funcionario responsable está investigando y actualizándose, para colaborar con sus compañeros, promoviendo de esta forma, un agradable clima organizacional y relaciones interpersonales; y a su vez, aplica el conocimiento al trabajo.

Es obvio que el profesional de la administración de la educación, está implementando distintas herramientas estratégicas que le han permitido, no solo impulsar el desarrollo del programa, y obtener ciertos objetivos asociados, sino también fortalecer otras áreas de la organización, que no se encuentran aisladas, sino que interactúan para garantizar el cumplimiento de los objetivos de la totalidad de la organización. Al respecto, es oportuno lo que expresó una de las personas entrevistas: "Se han integrado los objetivos del programa con el centro educativo, lo cual produjo mucho dinamismo tanto en los docentes como en los estudiantes, y donde cada asignatura es muy diferente".

Esa integración confirma la manifestación de Drucker (1999a), de que la producción de cambios es esencial, pues se está ante la presencia de una sociedad de organizaciones, cuyo principal recurso es el saber. 
De las consideraciones anteriores queda claro que el Programa de Innovaciones produce, en el centro educativo que se aplique (aunque sea transversalmente), cambios sumamente significativos, como el desarrollo de habilidades y destrezas que conducen a un incremento inevitable de la creatividad, la innovación y, en consecuencia, de conocimiento, a nivel tanto de la organización, como de los resultados obtenidos, lo cual es característico de la sociedad global actual. En la figura siguiente se muestra una síntesis de la producción de esos cambios y sus beneficios:

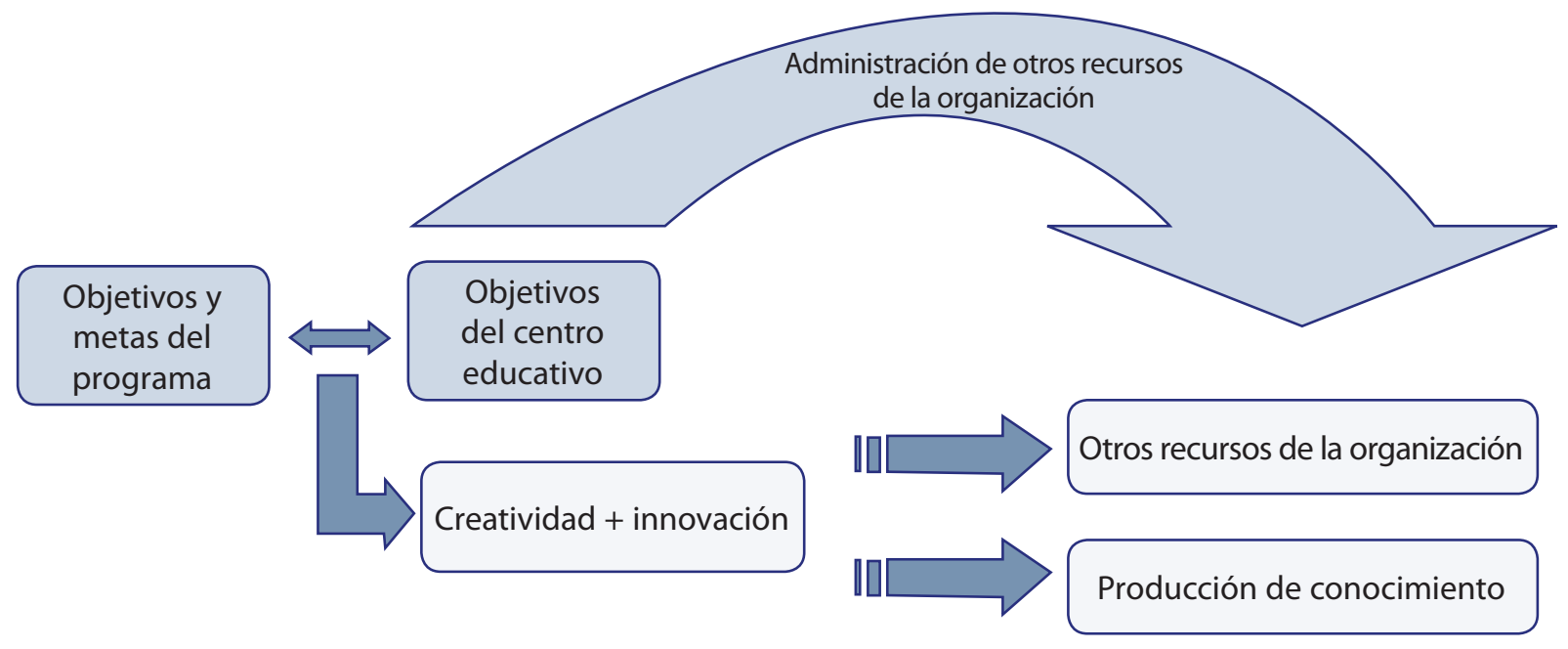

Figura 4. Objetivos propuestos por el Programa de Innovaciones, sus beneficios a la organización educativa, como un todo

Fuente: Elaboración propia, 2011.

Obviamente, desde la administración de la educación, el programa, como un componente más de la organización, posee objetivos, y otras características que contribuyen a que la organización alcance sus objetivos, como un todo, lo cual es palpable en dos de los tres centros educativos; en el otro se está en un proceso de cambio; tal y como se manifiesta en un extracto del trabajo de campo realizado: 
Tabla 14

Objetivos propuestos por el Programa de Innovaciones y sus beneficios a la organización educativa, como un todo

\begin{tabular}{|c|c|c|}
\hline Institución & Dirección & Funcionario responsable \\
\hline Colegio 1 & $\begin{array}{l}\text { Quedará para el 2012, establecerlo como un } \\
\text { eje transversal. }\end{array}$ & $\begin{array}{l}\text { Brindo colaboración, pero me saturan. } \\
\text { Provee el equipo, pero en las mejores } \\
\text { condiciones posibles, colaborando con el } \\
\text { recurso tecnológico. }\end{array}$ \\
\hline Colegio 2 & $\begin{array}{l}\text { Se han integrado los objetivos del programa } \\
\text { con el centro educativo, lo cual produjo mucho } \\
\text { dinamismo tanto en los docentes como en los } \\
\text { estudiantes, y donde cada asignatura es muy } \\
\text { diferente. }\end{array}$ & $\begin{array}{l}\text { El colegio, con el programa, se ha vuelto muy } \\
\text { activo, y lo refleja en las ferias científicas, } \\
\text { experimentos y proyectos que se desarrollan } \\
\text { en asignaturas como turismo. Se está en pro } \\
\text { del desarrollo tecnológico. }\end{array}$ \\
\hline Colegio 3 & $\begin{array}{l}\text { Si surge una necesidad, el profesor busca la } \\
\text { forma de estudiar, por lo tanto se enriquece, } \\
\text { se anima; para solventar esa necesidad. } \\
\text { Es decir, el profesor mejora. }\end{array}$ & $\begin{array}{l}\text { Le da más impulso a la investigación permite } \\
\text { sistematizar, facilitando la labor de los } \\
\text { profesores. }\end{array}$ \\
\hline
\end{tabular}

Fuente: Instrumento aplicado a los profesionales de la administración de la educación y funcionarios responsables del Programa de Innovaciones, 2011.

Tabla 15

Objetivos propuestos por el Programa de Innovaciones y sus beneficios a la organización educativa, como un todo; según asesor y supervisor

\begin{tabular}{cl}
\hline Profesional & \multicolumn{1}{c}{ Opinión expresada } \\
\hline Asesor & Integraron de tecnología en los procesos educativos. \\
& Hay clases entretenidas e innovadoras, con lo cual se trata de retener al estudiante. \\
Supervisor & Si, pues se incorpora la tecnología. \\
\hline
\end{tabular}

Fuente: Instrumento aplicado al asesor nacional asignado al Programa Nacional de Innovaciones, y al supervisor del circuito 09, de la dirección regional de educación San José Norte, Moravia, 2011. 


\section{Categoría de análisis: Sistemas de control utilizados en la gestión del Programa de Innovaciones}

\section{Eje temático: Evaluar procesos durante la puesta en marcha}

Indicador: la adecuada aplicación y cumplimiento de responsabilidades del personal docente

Para un profesional de la administración de la educación, controlar un centro educativo, en todos sus aspectos, es fundamental. Ante esta circunstancia, es importante la posición de Ivancevich et al. (1997), cuando manifiesta que los sistemas de control se basan en las medidas operativas, ya que controlan las operaciones a través del producto terminado, y permiten a los trabajadores evaluar los procesos a medida que se desarrollan.

Es decir, es significativa la labor del director, respecto de que es imprescindible que esté pendiente, tanto de lo que gira en torno a la aplicación del programa, como del centro educativo, para garantizar los resultados deseados. Al respecto, es importante la observación de Drucker (1999b) cuando acota: "Por tanto, la estimación de costos por actividad rinde no solamente un control de los costos, sino que cada vez más rinde control de resultados" (p. 157).

Ante esta circunstancia, es claro que el profesional de la Administración de la Educación considere, por medio de distintas acciones sistemáticas, la adecuada aplicación y cumplimiento de responsabilidades, mediante el control: en uno de ellos, el profesional en la administración de la educación manifestó: "Reviso planes de trabajo, hago visitas al laboratorio y a las aulas", y el otro: "doy pautas a seguir". En ambos casos, se manifiesta una forma a través de la cual, se aplica el control desde la administración de la educación, al respecto, es importante subrayar la observación de Chiavenato (2000), al manifestar que el control:

Verifica si todas las etapas marchan de conformidad con el plan trazado, las instrucciones dadas y los principios establecidos. Su objetivo es identificar las debilidades y los errores para rectificarlos y evitar que se repitan. (p. 92)

Debido a lo anterior, es importante subrayar que la persona que dirige el centro educativo, no solo está pendiente del cuidado de los recursos físicos (lo cual no se puede obviar), sino también, de la forma en la cual el Programa de Innovaciones es utilizado. Esto, constituye una herramienta indispensable, para el profesional de la administración de la educación, por cuanto está ejerciendo uno de sus deberes más importantes, como lo es verificar las responsabilidades (asociadas a la puesta en marcha, así como a los resultados obtenidos), no solo de la persona encargada del Programa de Innovaciones, sino de otros participantes; durante el desarrollo del mencionado programa. 
Además, desde la supervisión, en general, tal control se manifestó por medio de directrices, según expresó el supervisor: "En general, se coordinan capacitaciones y se giran directrices". Sin embargo, no se concretó directamente, nada asociado a capacitaciones con respecto al Programa de Innovaciones.

Desde la asesoría, el seguimiento y el control se delega al profesional de la administración de la educación, por lo cual, es oportuna la observación del asesor asignado al Programa de Innovaciones, cuando expresa: "Eso se canaliza por medio del director. El director da seguimiento y evaluación de las funciones de la persona responsable, a fin de año". Es decir, el superior directo del funcionario responsable del Programa, es la persona que dirige el centro educativo.

Es evidente que el control constituye una herramienta sumamente fundamental para la administración de la educación, pues es un mecanismo a través del cual es posible aumentar la calidad y alcanzar algunas metas definidas por el Consejo Superior de Educación, según lo que expresa el III Informe del Programa Estado de la Educación (2011):

El análisis de los centros educativos en conjunto de aspectos organizativos revela la existencia de culturas organizacionales poco favorables a la calidad y su lejanía con respecto a estándares cuya atención es clave para avanzar hacia las metas definidas por el CSE. (p. 149)

La dinámica respecto de la aplicación y cumplimiento de responsabilidades, se ilustra en la siguiente figura:

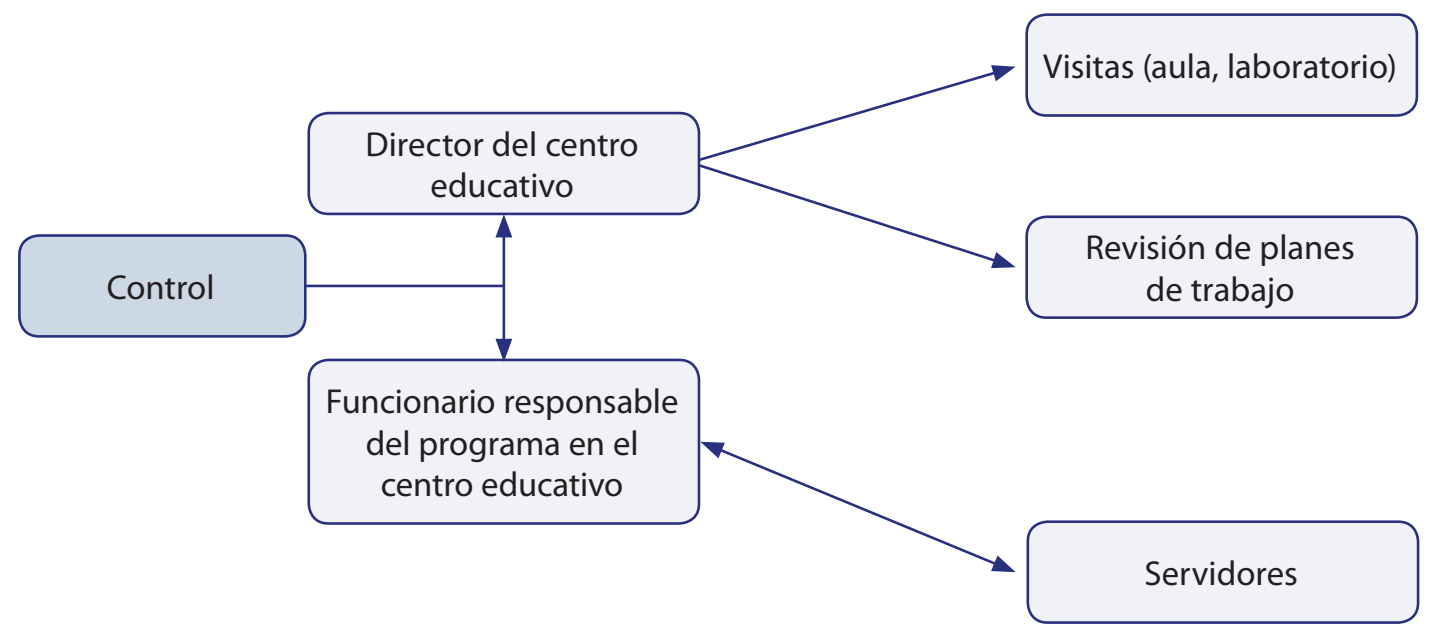

Figura 5. La adecuada aplicación y cumplimiento de responsabilidades del funcionario

Fuente: Elaboración propia, 2011. 
En la figura anterior, se ejemplifica la forma en la cual la dirección del centro educativo coordina con el responsable del programa, para verificar que se desarrolle de modo que garantice la obtención de los resultados deseados. Sin embargo, en los tres centros educativos, se proporciona un voto de confianza a los docentes, según se extrajo del instrumento aplicado:

Tabla 16

La adecuada aplicación y cumplimiento de responsabilidades del funcionario responsable

\begin{tabular}{|c|c|c|}
\hline Institución & Dirección & Funcionario responsable \\
\hline \multirow[b]{2}{*}{ Colegio 1} & \multirow{2}{*}{$\begin{array}{l}\text { La aplicación en realidad es un medio. } \\
\text { Doy pautas. }\end{array}$} & Es una función global del comité. \\
\hline & & $\begin{array}{l}\text { Hace visitas y luego revisa el estado en el } \\
\text { cual devuelven el equipo. }\end{array}$ \\
\hline Colegio 2 & $\begin{array}{l}\text { Visitas al aula, reuniones periódicas con el } \\
\text { comité de innovación. }\end{array}$ & $\begin{array}{l}\text { Realiza visitas, las cuales combina con la } \\
\text { directora, o lo por medio de un servidor. }\end{array}$ \\
\hline \multirow[b]{2}{*}{ Colegio 3} & \multirow{2}{*}{$\begin{array}{l}\text { Revisar planes de trabajo, visitas al } \\
\text { laboratorio y a las aulas. }\end{array}$} & Estoy disponible, presente y pendiente. \\
\hline & & $\begin{array}{l}\text { Existe una cultura de cómo se deben usar y } \\
\text { cuidar los equipos. }\end{array}$ \\
\hline
\end{tabular}

Fuente: Instrumento aplicado a los profesionales de la administración de la educación y funcionarios responsables del Programa de Innovaciones, 2011.

Tabla 17

La adecuada aplicación y cumplimiento de responsabilidades del funcionario, desde la perspectiva del asesor asignado al Programa Nacional de Innovaciones Educativas y del supervisor

\begin{tabular}{cl}
\hline Profesional & \multicolumn{1}{c}{ Opinión expresada } \\
\hline \multirow{2}{*}{ Asesor } & $\begin{array}{l}\text { Eso se canaliza por medio del director (El director da seguimiento y evaluación de las funciones } \\
\text { de la persona responsable, a fin de año). }\end{array}$ \\
& $\begin{array}{l}\text { Sin embargo, se les solicita un informe. } \\
\text { Supervisor }\end{array}$
\end{tabular}

Fuente: Instrumento aplicado al asesor nacional asignado al Programa Nacional de Innovaciones, y al supervisor del circuito 09, de la dirección regional de educación San José Norte, Moravia, 2011. 


\section{Categoría de análisis: Estrategias de evaluación implementadas en el desarrollo del Programa Nacional de Innovaciones}

\section{Eje temático: Adquisición de la calidad educativa}

Indicador: Obtención de resultados deseados en el centro educativo con la aplicación de la innovación propuesta por el programa o proyecto, al finalizar el curso lectivo.

Desde un punto de vista fundamental, llama la atención para este estudio que, con la aplicación del programa, se promueven muchas áreas de la organización, pues si bien es una forma a través de la cual se establece una interacción con el alumno, existe un ámbito en el cual se puede catalogar como un valor agregado con un significativo valor formativo, perceptible a mediano y/o largo plazo. Esto, lo expresó uno de los funcionarios responsables: "Se ha impulsado y desarrollado el software libre, en distintos proyectos y talleres de la institución. El beneficiado ha sido el alumno".

Esto evidencia que debido a la rapidez con que las nuevas tecnologías para la enseñanza se introducen en los centros educativos, y a la falta de experiencia en el uso y la gestión de esas tecnologías, es evidente la necesidad de investigar y evaluar las aplicaciones de estas nuevas tecnologías (Bates, 2000).

Ante esta circunstancia, en uno de los centros educativos, surgen ciertas necesidades, según expresó el director del colegio 1: "Se ha manifestado, pero con un matiz diferente, no como debería ser. Para impulsarlo, faltan más pizarras inteligentes, televisores de pantalla plana, y otros". Sin embargo, también se deben explotar los recursos que tienen, por el momento; pues son los indicados para obtener resultados, no solo a nivel de aprendizaje, sino de dominio de los grupos de estudiantes.

Es evidente que no solo se requiere administrar el Programa de Innovaciones sino también los recursos que tiene inmersos, tales como el equipo necesario para desarrollarlo; por lo cual es importante que desde la administración de la educación, se desarrolle la planificación requerida, para garantizar los recursos necesarios. Por esta razón, es acertado el aporte de Ivancevich et al. (1997) cuando expresa que por medio de la planificación, se determinan los objetivos y las metas, estableciendo las actividades o estrategias necesarias para lograr dichos objetivos.

En otra de las instituciones se ha implementado el Programa de Innovaciones, incluyendo los talleres que ofrece, de modo que es evidente que se subsana o se complementan el número de lecciones para aquellos docentes que no tienen tiempo completo, sino que también; implica que promueven el uso de software libre en distintos proyectos institucionales, según expresó la persona que dirige el colegio 2, al manifestar: 
"Hay aumento de lecciones para los profesores que imparten los talleres, hay diversidad en las alternativas o escogencias de talleres, por lo que llenan las expectativas y gustos de los estudiantes". Esto, a su vez, se complementa con la respuesta del otro colegio, en donde es claro que la implementación del programa, se impulsa desde la administración de la educación, según lo expresó la persona responsable: "Los resultados son buenos, se cumplen los objetivos. El programa es una herramienta didáctica tanto para el profesor como para el estudiante. Es una forma de generar técnicas de enseñanza diferentes".

Ante esto, es importante acotar la imprescindible labor de los profesionales en la Administración de la Educación, quienes con una diversidad de acciones estratégicas puedan implementar el Programa de Innovaciones, durante el ciclo lectivo, de modo que, paulatinamente, se plasme en la organización educativa la calidad educativa a la cual aspira. Es por esta razón, que es oportuno señalar la posición de Whitaker (1998), cuando expresa: "La gestión de la calidad parte de la idea de que cualquier cosa puede hacerse mejor de lo que es, y de la noción de que toda mejora cuenta, aunque a primera vista sea insignificante" (p. 187).

De este modo, con su liderazgo, pueden implementar distintas acciones sistemáticas para que, a través del programa, la creatividad y la innovación adquieran mayor relevancia y protagonismo, en la organización educativa. Lo anterior se explica en la siguiente figura:

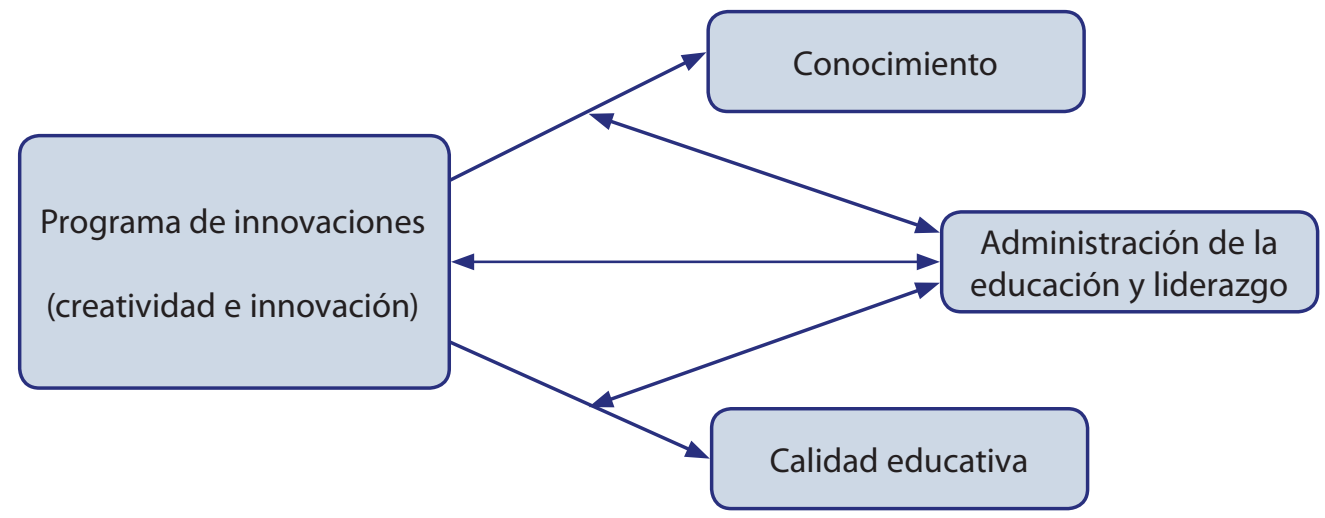

Figura 6. Obtención de resultados deseados en el centro educativo con la aplicación de la innovación propuesta por el Programa o proyecto, al finalizar el curso lectivo.

Fuente: Elaboración propia, 2011. 


\section{Del trabajo de campo realizado, se extrajo lo siguiente:}

Tabla 18

Obtención de resultados deseados en el centro educativo con la aplicación de la innovación propuesta por el Programa o proyecto, al finalizar el curso lectivo

\begin{tabular}{|c|c|c|}
\hline Institución & Dirección & Funcionario responsable \\
\hline \multirow{3}{*}{ Colegio 1} & \multirow{3}{*}{$\begin{array}{l}\text { Se ha manifestado, pero con un matiz } \\
\text { diferente, no como debería ser. Para } \\
\text { impulsarlo más, faltan pizarras inteligentes, } \\
\text { televisores de pantalla plana, y afines. }\end{array}$} & $\begin{array}{l}\text { Constituye un valor agregado a la materia que } \\
\text { imparten. Les ha dado resultado. }\end{array}$ \\
\hline & & $\begin{array}{l}\text { Las ocasiones en las que los he visitado, se ha } \\
\text { manifestado mayor concentración y dominio } \\
\text { de los grupos. }\end{array}$ \\
\hline & & Los estudiantes conocen de tecnología. \\
\hline & Aumento de lecciones para los profesores. & y desarroll \\
\hline Colegio 2 & $\begin{array}{l}\text { Diversidad en las alternativas o escogencias } \\
\text { de talleres, por lo que llenan las expectativas } \\
\text { y gustos de los estudiantes, que es la razón de } \\
\text { ser de la dirección. }\end{array}$ & $\begin{array}{l}\text { libre, en distintos proyectos y talleres de } \\
\text { la institución; cuyo beneficiario ha sido el } \\
\text { alumno, razón de ser de la institución en } \\
\text { general. }\end{array}$ \\
\hline \multirow[t]{2}{*}{ Colegio 3} & $\begin{array}{l}\text { Los resultados son buenos, se cumplen los } \\
\text { objetivos. El programa es una herramienta } \\
\text { didáctica tanto para el profesor como para el } \\
\text { estudiante. }\end{array}$ & $\begin{array}{l}\text { Los resultados han sido positivos; pues ha } \\
\text { facilitado la razón de ser de la institución: } \\
\text { fortalecer el proceso de aprendizaje (para el } \\
\text { alumno). Así como también, la enseñanza. }\end{array}$ \\
\hline & $\begin{array}{l}\text { Es una forma de generar técnicas de } \\
\text { enseñanza diferentes. }\end{array}$ & $\begin{array}{l}\text { Proporciona herramientas poderosas, como } \\
\text { linux, para facilitar esos procesos. }\end{array}$ \\
\hline
\end{tabular}

Fuente: Instrumento aplicado a los profesionales de la Administración de la Educación y funcionarios responsables del Programa de Innovaciones, 2011.

Tabla 19

Obtención de resultados daeseados en el centro educativo con la aplicación de la innovación propuesta por el Programa o proyecto, al finalizar el curso lectivo; según asesor y supervisor

Profesional Opinión expresada

Transformación innovadora de los procesos educativos.

Asesor

Poner al estudiante en contacto con nuevas tecnologías, gracias a la intervención de los directores.

Se ha roto la brecha digital a nivel rural, que era muy evidente.

Se proporcionó acceso a recursos como la conectividad.

Supervisor

Se incorpora la tecnología a las instituciones, lo cual contribuye a producir un cambio gradual en los estudiantes.

Fuente: Instrumento aplicado al asesor nacional asignado al Programa Nacional de Innovaciones, y al supervisor del circuito 09, de la dirección regional de educación San José Norte, Moravia, 2011. 


\section{Síntesis de la sistematización y análisis de resultados.}

El Programa Nacional de Innovaciones Educativas constituye una herramienta fundamental para cualquier centro educativo, si se considera el contexto de la sociedad global actual. Sin embargo, es evidente que la forma en la cual se ha implementado el Programa de Innovaciones, en cada uno de los tres centros educativos; depende, en gran medida, de las distintas acciones sistemáticas que se realicen desde la administración de la educación.

Debido a lo anterior, llamó la atención para este estudio, dos aspectos sumamente importantes para el desarrollo en una organización, uno de ellos apunta a la desarticulada relación y de coordinación, entre el profesional de la administración de la educación y el encargado del Programa de Innovaciones Educativas, en el colegio 1, lo cual no ha permitido, hasta el momento, el uso adecuado del Programa de Innovaciones. Además, el Programa de Innovaciones demanda la presencia tanto de un analista, como de un docente de innovación; sin embargo, debido a que en este centro educativo, únicamente está el analista, es imprescindible aplicar una herramienta estratégica, que permita desde la administración de la educación, impulsar a través de un liderazgo dinámico e innovador, acciones que favorezcan, que cada uno de los integrantes de la organización, implementen adecuadamente, el Programa de Innovaciones.

Es por esta razón, que se presentó una propuesta de intervención desde la administración de la educación, enfocada a incorporar el Programa Nacional de Innovaciones Educativas (y por lo tanto el uso de software libre); a un plan institucional y/o plan operativo anual de la institución.

\section{Conclusiones}

Es importante que la implementación eficiente del Programa Nacional de Innovaciones Educativas, sea una oportunidad para que la administración de la educación se desarrolle en forma adecuada en la organización, propiciando la creatividad y la innovación; componentes indispensables para enfrentar los retos de la sociedad global actual; lo cual conduce al cumplimiento de los fines y objetivos de la educación costarricense.

En el colegio 1, la adaptación mutua (uno de los mecanismos de coordinación), no se ha desarrollado de la mejor manera posible, pues desde la administración de la educación no se ha manifestado apertura para que el Programa Nacional de Innovaciones Educativas, trabaje adecuadamente. También, esto se debe a la sobrecarga de las funciones del profesional de la administración de la educación (quien tiene poco tiempo de laborar en la institución); así como de las funciones del encargado del programa nacional de innovaciones; situación que sesga en 
parte la labor, en el marco del Programa Nacional de Innovaciones Educativas. Sin embargo, los mecanismos de coordinación sí se manifiestan satisfactoriamente en los otros dos colegios, mediante la disponibilidad y flexibilidad de la comunicación.

La comunicación no se desarrolla de una forma idónea en el colegio 1, no propicia la realimentación ni el compromiso desde la administración de la educación, lo que limita la formación de equipos de trabajo, así como la detección de aspectos positivos y/o negativos, durante la aplicación del Programa Nacional de Innovaciones Educativas.

Por esta razón, debido a que no hay un adecuado canal de comunicación entre el analista y el director del colegio 1, no se pueden desarrollar los talleres y/o otros tópicos del Programa Nacional de Innovaciones Educativas; lo que produce que no se planteen objetivos claros, respecto de la aplicación del Programa en mención.

Respecto de la estructura de organización del Programa Nacional de Innovaciones Educativas, es relevante que el encargado del colegio 1, desconoce que el programa funciona con otra perspectiva, muy diferente para lo que fue realmente creado, según se contempla en el organigrama de la institución. Por otra parte, existe un comité en los tres centros educativos, integrado por personal altamente capacitado. Este comité, en el colegio 1, constituye una entidad fiscalizadora, que entrega inventarios; mientras que en los dos centros educativos, funciona como un ente motivador, impulsando el desarrollo de la creatividad y la innovación.

Desde el punto de vista del proceso de planificación, otro factor que se debe considerar desde la administración de la educación, en el contexto en el que actualmente se desarrolla la administración de las organizaciones educativas, es la claridad con la cual se deben plantear los fines y objetivos de la organización; partiendo de la filosofía institucional. Desde esta perspectiva, es oportuno señalar que en la filosofía institucional de los centros educativos, tienen implícita, de una u otra forma, la innovación; lo cual es un parámetro sumamente importante; pues aunado a esto, se utiliza el Programa Nacional de Innovaciones Educativas.

Es decir, existe una relación entre los objetivos y metas institucionales (en los tres centros educativos), y el programa; sin embargo, en el colegio 1, se puede establecer una intervención, desde la gestión, que desemboque en articular el Programa Nacional de Innovaciones Educativas con los objetivos de la organización educativa; de tal forma que contribuya a cumplir su función, como lo es la producción de conocimiento y la formación integral del estudiante.

Dadas las consideraciones anteriores, es evidente que la producción del conocimiento, desde la administración de la educación, se propicia con la incorporación del software libre, propuesto por el Programa Nacional de Innovaciones Educativas; de tal manera que no solo se permite estudiar a profundidad una aplicación de cómputo; sino que adicionalmente, se impulsa el desarrollo de la creatividad y la innovación que se practica en el programa. 
Al respecto, en el colegio 1, falta impulsar esta iniciativa, para explotar todo el potencial que brinda el uso de un sistema libre y gratuito; mientras que en los otros dos colegios, el proceso de planificación se manifiesta cuando los objetivos y las metas del Programa Nacional de Innovaciones Educativas se incorporan al centro educativo, propiciando el desarrollo de habilidades y destrezas que aumentan la creatividad y la innovación.

Desde el punto de vista de los sistemas de control, es importante subrayar que, para fomentar y forjar la proactividad y dinamismo que faltan en el centro educativo 1, es importante no limitarse a recibir y revisar informes (que son para el director y el supervisor, una forma de dar seguimiento), sino también observar, y verificar qué aspectos del Programa de Innovación, se están aplicando en el centro educativo (tanto por los docentes, como por los estudiantes), de modo que se genere calidad educativa.

Por otra parte, los otros dos centros educativos coinciden en una articulación entre el funcionario responsable y el profesional de la administración de la educación, cuando ambos coordinan el control del adecuado desarrollo del Programa Nacional de Innovaciones Educativas; mediante acciones sistemáticas como visitas al aula.

Además, las estrategias de evaluación empleadas constituyen una herramienta sumamente útil, para describir y conocer en qué medida, el programa cumple con las expectativas planteadas por la organización. Por eso, la aplicación del Programa Nacional de Innovaciones Educativas, en las instituciones objeto de este estudio (sobre todo en el colegio 1), puede generar los resultados deseados, siempre y cuando desde la gestión, se utilicen las estrategias innovadoras fundamentales, para desarrollarlo; como lo es incentivar, en los miembros de la organización educativa, tanto la naturaleza de la sociedad global actual, como las múltiples ventajas que implica el uso de software libre, propuesto por el Programa de Innovaciones Educativas.

Las estrategias de evaluación en los otros dos centros educativos, se han manifestado mediante el liderazgo del profesional de la administración de la educación, desarrollando talleres, exposiciones y/o otros; en los cuales se plasma el Programa Nacional de Innovaciones Educativas.

Debido a lo anterior, llamó la atención para este estudio, dos aspectos sumamente importantes para el desarrollo en una organización, uno de ellos es la falta de coordinación entre el profesional de la administración de la educación y el encargado del Programa Nacional de Innovaciones Educativas en el colegio 1, lo cual no ha permitido, hasta el momento, el uso adecuado del Programa de Innovaciones. Además, el Programa Nacional de Innovaciones Educativas demanda la presencia tanto de un analista como de un docente de innovación; sin embargo, debido a que no se puede tener a los dos profesionales en este centro educativo, es imprescindible, aplicar una herramienta estratégica, como una adecuada coordinación y/o 
planificación, que permita desde la administración de la educación a cada uno de los docentes que forman parte de la organización, constituirse en el docente de innovación que requiere el Programa Nacional de Innovaciones Educativas, en la organización educativa.

Por esto, se presentó una propuesta de intervención desde la administración de la educación, denominada: "El desarrollo de la creatividad y la innovación en las organizaciones educativas: Una propuesta desde la gestión moderna de la educación", con la finalidad de que el profesional de la administración de la educación incorpore el Programa Nacional de Innovaciones Educativas en su organización educativa.

\section{Referencias}

Barrantes, R. (2004). Investigación: un camino al conocimiento, un enfoque cualitativo y cuantitativo. San José, Costa Rica: EUNED.

Bates, A. W. (2000). Cómo gestionar el cambio tecnológico. Estrategias para los responsables de centros universitarios. Barcelona: Gedisa.

Castells, M. (2000). The rise of the Network Society. Massachusetts: Blackwell Publishers.

Chiavenato, I. (2000). Introducción a la teoría general de la administración. México DF: MacGrawHill.

Chiavenato, I. (2009). Comportamiento organizacional. La dinámica del éxito en las organizaciones. México DF: MacGraw-Hill.

Cobo R., J. C. (abril, 2009). Conocimiento, creatividad y software libre: una oportunidad para la educación en la sociedad actual. Revista sobre la sociedad del conocimiento, 8, 1-9. Recuperado de http://redalyc.uaemex.mx/redalyc/src/inicio/ArtPdfRed.jsp?iCve=79015644007

Correa de Molina, C. (2004). Gestión y evaluación de la calidad de la educación. Referentes generales para la acreditación. Bogotá, Colombia: Editorial Magisterio.

David, F. (2008). Conceptos de administración estratégica. México: Pearson Educación.

Drucker, P. (1999a). La sociedad poscapitalista. Buenos Aires: Sudamericana.

Drucker, P. (1999b). Los desafíos de la gerencia para el siglo XXI. Bogotá, Colombia: Grupo Editorial Norma.

Fernández-Ballesteros, R. (2001). Evaluación de Programas. Una guía práctica en ámbitos sociales, educativos y de salud. Madrid: Editorial Síntesis. 
Garbanzo V., G.M. y Orozco D., V.H. (2007). Desafíos del sistema educativo costarricense: un nuevo paradigma de la administración de la educación. Revista Educación, 31(2), 95-110.

Garbanzo V., G.M. y Orozco D., V.H. (2010). Liderazgo para una gestión moderna de procesos educativos. Revista Educación, 34(1), 15-29. Recuperado en: http://redalyc.uaemex.mx/ redalyc/pdf/440/44013961001.pdf

Hernández, R.; Fernández, C. y Baptista, P. (1998). Metodología de la investigación. México: McGraw-Hill.

Ivancevich, J. M., Lorenzi, P., Skinner, S. J. y Crosby, P. (1997). Gestión, calidad y competitividad. Madrid: McGraw-Hill.

Maidagán, M. J., Iñaqui, C., Garagalza, L. y Arrizabalaga, G. (2009). Filosofía de la innovación. El papel de la creatividad en un mundo global. Madrid: Plaza y Valdés.

Majó, J. y Marqués, P. (2001). La revolución educativa en la era Internet. Valencia, España: Praxis.

Ministerio de Educación Pública. (2006). Propuesta de estructura plan de estudios de Colegios de Innovación Educativa con el uso de tecnología de punta. Acuerdo 010506. Consejo Superior de Educación. San José, Costa Rica: Autor.

Mintzberg, H. y Quinn, J. B. (1993). El proceso estratégico: conceptos, contextos y casos. México: Prentice Hall.

Ornelas, D. J. (setiembre-diciembre, 2007). Volver al desarrollo. Revista Aportes, 12(36), 5-24. Recuperado en: http://redalyc.uaemex.mx/src/inicio/ArtPdfRed.jsp?iCve=37612480002

Programa Estado de la Educación. (2011). III Informe Estado de la Educación. San José, Costa Rica: Autor.

Rodríguez, W. (1999). El legado de Vygostki y de Piaget a la educación. Revista Latinoamericana de Psicología, 31(3), 477-489. Recuperado de http://redalyc.uaemex.mx/pdf/805/80531304.pdf

Salas, F. (2003). La administración educativa y su fundamentación epistemológica. Revista Educación, 27 (1), 9-6. Recuperado de http://redalyc.uaemex.mx/pdf/440/44027102.pdf

Velasco, P. (2007). Psicología y creatividad: una revisión histórica (Desde los autorretratos de los genios del siglo XIX hasta las teorías implícitas del siglo XX). Caracas, Venezuela: Editorial de Humanidades.

Whitaker, P. (1998). Cómo gestionar el cambio en contextos educativos. Madrid: Narcea. 
Anexo A

\section{Entrevita dirigida al director o directora del Centro Educativo}

Universidad de Costa Rica

Sistema de Estudios de Posgrado

Facultad de Educación

Escuela de Administración Educativa

Entrevista dirigida al director o directora del Centro Educativo

Por este medio solicito, respetuosamente, su colaboración para realizar una entrevista cuyo objetivo es analizar la gestión de las organizaciones educativas respecto de la implementación del Programa Nacional de Innovaciones Educativas en tres instituciones del circuito 09 de la Dirección Regional San José Norte. La investigación corresponde a un estudio de la Maestría en Ciencias de la Educación con énfasis en Administración Educativa. La información que usted proporcione, será completamente confidencial, y al mismo tiempo, tendrá un aporte invaluable, pues sin duda alguna contribuirá a fortalecer la calidad del sistema educativo público costarricense.

I PARTE: INFORMACIÓN GENERAL: Marque con una equis ("x") la opción que más se aproxima a su condición o complete los espacios en blanco según corresponda:

\begin{tabular}{|c|c|c|}
\hline $\begin{array}{l}\text { 1.1 Formación original como docente: (por } \\
\text { ejemplo: profesor de matemática o español) }\end{array}$ & $\begin{array}{l}\text { 1.2 Sexo: } \\
\text { ( ) Masculino } \\
\text { ( ) Femenino }\end{array}$ & 1.3 Edad: __ años \\
\hline $\begin{array}{l}\text { 1.4 Años de ejercer la docencia: } \\
\text { 1.5 Años } \\
\text { de director: } \quad \text { años de experiencia de ejercer la función }\end{array}$ & $\begin{array}{l}\text { 1.6 Grado académico más } \\
\text { alto: }\end{array}$ & $\begin{array}{l}\text { 1.7 Año en que obtuvo } \\
\text { su último grado } \\
\text { académico: }\end{array}$ \\
\hline $\begin{array}{l}\text { 1.8 Condición laboral en la institución que dirige: } \\
\begin{array}{ll}\text { ( ) Propiedad } & \text { ( ) Interino }\end{array}\end{array}$ & 1.9 Categoría profesional: & $\begin{array}{l}\text { 1.10 Tipo de dirección } \\
\text { del centro educativo } \\
\text { que usted dirige: }\end{array}$ \\
\hline
\end{tabular}

\section{PARTE: Mecanismos de coordinación}

2.1 ¿Cómo conoció usted el Programa de Innovaciones Educativas?

2.2 ¿En qué se basa para la formación de equipos de trabajo que ejecuten el programa en su institución? 
2.3 ¿Cuál fue el medio que utilizó usted para comunicarle al resto del personal docente la aplicación y las pautas a seguir para implementar el programa conocido como innovaciones en el centro educativo que usted dirige?

2.4 ¿Cómo desarrolla o promueve la fluidez y dinamismo de comunicación, durante la aplicación del Programa de Innovación?

2.5 ¿Cómo asigna y monitorea las responsabilidades durante el desarrollo del Programa de Innovaciones?

2.6 ¿De qué forma especifica y/o programa al personal docente, el trabajo que debe realizar, para implementar el programa?

2.7 ¿Qué medios utiliza usted para comunicar al personal los resultados, de acuerdo a los objetivos que se deben alcanzar con el programa?

2.8 ¿Cuenta la institución con el personal idóneo para asignar las tareas que implica la aplicación del programa?

2.9 ¿Cómo se asegura que el funcionario conoce lo que se espera de él, en el marco de la aplicación del programa?

2.10 ¿Cómo verifica que el funcionario comparte su conocimiento y habilidades con el resto de sus compañeros, para alcanzar los objetivos propuestos en el programa?

\section{PARTE: Estructura de organización}

3.1 ¿Cuenta su institución con un manual descriptivo de puestos, acorde con los objetivos que se desean alcanzar con la implementación del programa?

3.2 ¿Existe un organigrama en su institución que visualice la división del trabajo?, ¿cómo procedió para su elaboración?

3.3 ¿Cómo incorpora usted en el organigrama de su institución, el Programa de Innovaciones para que se visualice de forma clara ante los miembros del centro educativo?

3.4 ¿Cómo se desarrolla el Programa de Innovaciones en las distintas áreas académicas de su institución?

3.5 ¿Qué criterios considera usted en la formación del comité u otro grupo que participe en el adecuado desarrollo del Programa de Innovaciones?

\section{PARTE: Proceso de planificación}

4.1 ¿De qué forma se incluye el programa en el POA de su institución?

4.2 ¿Cómo selecciona el personal idóneo e interesado para desarrollar los objetivos del programa?

4.3 ¿De qué forma canaliza o promueve usted en los distintos departamentos, la implementación del programa en su institución?

4.4 ¿Qué tipo de equipo de cómputo e infraestructura dispone el centro educativo para desarrollar el programa? 
4.5 ¿Ha interactuado de alguna forma con las autoridades respectivas para desarrollar el programa, de modo que se promueva la voluntad política requerida?

4.6 ¿De qué forma ha considerado los fines y objetivos del Programa de Innovaciones en la filosofía institucional?

4.7 ¿Cuenta su institución con un mecanismo a través del cual regule el desarrollo de las directrices propuestas por el MEP, con respecto a la aplicación del programa?

4.8 ¿Cómo contribuyen los objetivos y metas propuestas por el Programa de Innovaciones, en beneficio del centro educativo?

4.9 ¿Cómo contribuyen los objetivos y metas propuestas por el programa, con los propuestos por su centro educativo, como un todo?

4.10 ¿Qué tipo de actividades utiliza usted para desarrollar un plan de acción, que le permita lograr los objetivos del programa?

4.11 ¿Qué tipo de precauciones o previsiones toma usted en cuenta, ante la aplicación del programa?

4.12 ¿Cómo coordina usted con el funcionario responsable, los distintos requerimientos físicos que se necesitan para el desarrollo del programa?

4.13 ¿De qué forma coordina con la autoridad competente del MEP, la asignación del funcionario idóneo que aplique adecuadamente el Programa de Innovación?

4.14 ¿En cuáles criterios se funda para seleccionar, motivar y promover la capacitación del funcionario responsable del programa?

4.15 ¿Cómo aplica, en coordinación con el funcionario responsable, la delegación de distintos tareas asociadas con la ejecución del programa, orientada a cumplir los objetivos propuestos?

4.16 ¿En cuál información se basa para verificar y promover la realimentación, para mejorar la ejecución de la innovación propuesta por el programa, en los miembros de su centro educativo?

4.17 ¿Cuáles acciones realiza usted para monitorear que los resultados obtenidos, corresponden con los resultados deseados?

\section{PARTE: Sistemas de control}

5.1 ¿Qué tipo de acciones o mecanismos usa para monitorear la adecuada aplicación y cumplimiento de responsabilidades por parte del personal responsable, con respecto a la aplicación del programa?

5.2 ¿De qué forma coordina con la Asesoría del MEP respectiva, para verificar o monitorear la adecuada aplicación del Programa de Innovación?

5.3 ¿Cuáles cambios se han manifestado con respecto al porcentaje de promoción, de los estudiantes que participan en el programa? 


\section{PARTE: Estrategias de evaluación}

6.1 ¿De qué forma cuenta con un sistema de evaluación exclusivo para el alumno que participe directamente en el Programa de Innovación?, ¿por qué?

6.2 ¿El informe o documento emitido por el responsable de la aplicación del Programa de Innovación en su institución, cumple con las expectativas de los objetivos planteados?

6.3 ¿Cuáles han sido los resultados obtenidos, con respecto a la implementación del programa en su institución?

Comentario:

¡Gracias por su colaboración! 
Anexo B

Entrevista dirigida al funcionario responsable del programa en el Centro Educativo

Universidad de Costa Rica

Sistema de Estudios de Posgrado

Facultad de Educación

Escuela de Administración Educativa

Entrevista dirigida al funcionario responsable del programa en el centro educativo

Por este medio solicito, respetuosamente, su colaboración para realizar una entrevista cuyo objetivo es analizar la gestión de las organizaciones educativas respecto de la implementación del Programa Nacional de Innovaciones Educativas en tres instituciones del circuito 09 de la Dirección Regional San José Norte. La investigación corresponde a un estudio de la Maestría en Ciencias de la Educación con énfasis en Administración Educativa. La información que usted proporcione, será completamente confidencial, y al mismo tiempo, tendrá un aporte invaluable, pues sin duda alguna contribuirá a fortalecer la calidad del sistema educativo público costarricense.

\section{ENTREVISTA DIRIGIDA AL FUNCIONARIO RESPONSABLE EN EL CENTRO EDUCATIVO}

I PARTE: INFORMACIÓN GENERAL: Marque con una equis (" $x$ ") la opción que más se aproxima a su condición o complete los espacios en blanco según corresponda:

\begin{tabular}{|c|c|c|c|c|c|}
\hline & Años de experiencia: ___ años & & $\begin{array}{l}\text { Sexo: } \\
\text { ( ) Masculino } \\
\text { ( ) Femenino }\end{array}$ & 1.3 & años \\
\hline 1.4 & $\begin{array}{l}\text { Años de experiencia de ejercer la función de } \\
\text { responsable del programa:__años }\end{array}$ & 1.5 & $\begin{array}{l}\text { Grado académico } \\
\text { más alto: }\end{array}$ & 1.6 & $\begin{array}{l}\text { Año en que obtuvo } \\
\text { su último grado } \\
\text { académico: }\end{array}$ \\
\hline 1.7 & $\begin{array}{l}\text { Condición laboral: } \\
\text { ( ) Propiedad ( ) Interino }\end{array}$ & 1.8 & $\begin{array}{l}\text { Categoría } \\
\text { profesional: }\end{array}$ & 1.9 & $\begin{array}{l}\text { Tipo de función que } \\
\text { usted cumple: } \\
\text { ( ) Analista } \\
\text { ( ) Docente } \\
\text { ( ) Otro: }\end{array}$ \\
\hline
\end{tabular}

\section{PARTE: Mecanismos de coordinación}

2.1 ¿Qué llamó la atención del programa o proyecto de Innovaciones Educativas?

2.2 ¿Qué criterios utiliza para trabajar en equipo, el programa con sus compañeros?

2.3 ¿De qué forma coordina usted con el director el adecuado desarrollo del programa? 
2.4 Como responsable, ¿qué criterios utiliza para monitorear, en conjunto con el director, el adecuado uso de los recursos de los que dispone?

2.5 ¿Cuáles acciones utiliza usted para programar (o especificar), el trabajo que implica aplicar el programa en la institución, con sus demás compañeros?

2.6 ¿De qué forma, en coordinación con el director, le comunica a sus compañeros los resultados obtenidos de las innovaciones propuestas por el programa, según los objetivos?

2.7.a ¿Bajo qué circunstancias aplica sus conocimientos de modo que se fortalezca su función, en el centro educativo con respecto a la aplicación de programa?

2.7.b ¿Cuál es el rol que cumple usted en el centro educativo, para que el programa (y todo lo que implica), funcione correctamente?

2.8 ¿De qué forma comparte con sus compañeros sus conocimientos y habilidades, para alcanzar los objetivos propuestos en el programa?

\section{PARTE: Estructura de organización}

3.1 ¿Conoce usted un manual descriptivo de puestos en el que se refleje su función, acorde con los objetivos que se desean alcanzar?

3.2 ¿De qué forma, en el organigrama de su institución, se visualiza una división del trabajo de los integrantes del centro educativo?

3.3 ¿Cómo se incorporan en el organigrama del centro educativo, el programa de modo que lo visualicen todos los integrantes de la organización?, ¿qué recomendaciones le haría a su director al respecto?

3.4 ¿De qué forma impulsa usted el programa en las distintas áreas académicas de la institución?

3.5 ¿Qué criterios considera usted, en conjunto con el director, con respecto a la formación del comité u otro grupo que participe en el adecuado desarrollo del programa?

\section{PARTE: Proceso de planificación}

4.1 ¿De qué forma promueve usted, en conjunto con el director, la incorporación del programa en el POA del centro educativo?

4.2 ¿En qué criterios se basa para seleccionar a los docentes, según los objetivos propuestos por el programa?

4.3 ¿Cómo promueve la participación de los distintos docentes (por departamentos), en el programa?

4.4 ¿Cómo canaliza en conjunto con la autoridad competente, los requerimientos que debe tener la institución con respecto a infraestructura y equipo de cómputo necesario y adecuado para el desarrollo del programa? 
4.5 ¿De qué forma mantiene contacto o comunicación con las autoridades respectivas para el desarrollo del programa en el centro educativo, de modo que se promueva la voluntad política requerida?

4.6 ¿De qué manera están los fines y objetivos del Programa de Innovaciones, plasmados en la filosofía institucional?

4.7 ¿Cuenta su institución con un mecanismo a través del cual regule el desarrollo de las directrices propuestas por el MEP, con respecto a la aplicación del programa?

4.8 ¿Cómo contribuyen los objetivos y metas propuestas por el Programa de Innovaciones, en beneficio del centro educativo?

4.9 ¿Cómo contribuyen los objetivos y metas propuestas por el programa, con los propuestos por su centro educativo, como un todo?

4.10 ¿Qué tipo de actividades utiliza usted para desarrollar un plan de acción, que le permita lograr los objetivos del programa?

4.11 ¿Qué tipo de precauciones o previsiones toma usted en cuenta, en conjunto con una autoridad competente, ante la aplicación del programa?

4.12 ¿Cómo coordina usted, los distintos requerimientos físicos que se necesitan para el desarrollo del programa?

4.13 ¿De qué forma coordina tanto con la autoridad competente del MEP, como con la dirección, su incorporación al centro educativo en el cual labora, para aplicar adecuadamente el programa?

4.14 ¿En cuáles criterios se funda para seleccionar, motivar y promover, en conjunto con su director, la capacitación que usted requiere?

4.15 ¿Cómo aplica, en coordinación con el director, la delegación de distintas tareas asociadas con la ejecución orientada a cumplir los objetivos propuestos?

4.16 ¿En cuál información se basa para verificar y promover la realimentación, para mejorar la ejecución del programa en los miembros de su centro educativo?

4.17 ¿Cuáles acciones realiza usted para monitorear que los resultados obtenidos, corresponden con los resultados deseados?

\section{PARTE: Sistemas de control}

5.1 ¿Qué tipo de acciones o mecanismos usa para monitorear la adecuada aplicación y cumplimiento de responsabilidades por parte del personal con el que usted labora, con respecto a la aplicación del programa?, ¿las combina de alguna forma con su director?

5.2 ¿De qué forma coordina con la Asesoría del MEP respectiva para verificar o monitorear la adecuada aplicación del Programa de Innovación?

5.3 ¿Cuáles cambios se han manifestado con respecto al porcentaje de promoción, de los estudiantes que participan en el programa? 


\section{PARTE: Estrategias de evaluación}

6.1 ¿Cuenta con un sistema de evaluación exclusivo para el alumno que participe directamente en el Programa de Innovación?, ¿por qué?

6.2 ¿El informe o documento que usted elabora, como responsable de la aplicación del Programa de Innovación en su institución, cumple con las expectativas de los objetivos planteados?

6.3 ¿Cuáles han sido los resultados obtenidos, con respecto a la implementación del programa en su institución?

Comentario:

¡Gracias por su colaboración! 
Anexo C

Entrevista dirigida al supervisor del Circuito

Universidad de Costa Rica

Sistema de Estudios de Posgrado

Facultad de Educación

Escuela de Administración Educativa

Entrevista dirigida al Supervisor del Circuito

Por este medio solicito, respetuosamente, su colaboración para realizar una entrevista cuyo objetivo es analizar la gestión de las organizaciones educativas respecto de la implementación del Programa Nacional de Innovaciones Educativas en tres instituciones del circuito 09 de la Dirección Regional San José Norte. La investigación corresponde a un estudio de la Maestría en Ciencias de la Educación con énfasis en Administración Educativa. La información que usted proporcione, será completamente confidencial, y al mismo tiempo, tendrá un aporte invaluable, pues sin duda alguna contribuirá a fortalecer la calidad del sistema educativo público costarricense.

Entrevista dirigida al Supervisor del Circuito

I PARTE: INFORMACIÓN GENERAL: Marque con una equis (" $x$ ") la opción que más se aproxima a su condición o complete los espacios en blanco según corresponda:

\begin{tabular}{|c|c|c|c|c|c|}
\hline 1.1 & $\begin{array}{l}\text { Formación original como docente: (por } \\
\text { ejemplo: profesor de matemática o español) }\end{array}$ & & $\begin{array}{l}\text { Sexo: } \\
\text { ( ) Masculino } \\
\text { ( ) Femenino }\end{array}$ & 1.3 & _años \\
\hline 1.4 & $\underbrace{}_{\text {Años de ejercer la docencia: }}$ años & 1.6 & $\begin{array}{l}\text { Grado académico } \\
\text { más alto: }\end{array}$ & 1.7 & $\begin{array}{l}\text { Año en que obtuvo } \\
\text { su último grado } \\
\text { académico: }\end{array}$ \\
\hline 1.5 & $\begin{array}{l}\text { Años de experiencia de ejercer la función de } \\
\text { supervisor: } \quad \text { años }\end{array}$ & & & & \\
\hline 1.8 & $\begin{array}{l}\text { Condición laboral en la que se encuentra: } \\
\text { ( ) Propiedad ( ) Interino }\end{array}$ & 1.9 & Categoríaprofesional: & & \\
\hline
\end{tabular}

\section{PARTE: Mecanismos de coordinación}

2.1 ¿Cómo conoció usted el Programa de Innovaciones Educativas?

2.2 ¿Cómo asigna y monitorea las responsabilidades durante el desarrollo del Programa de Innovaciones, en las instituciones participantes? 
2.3 ¿Qué medios utiliza usted para comunicar al personal involucrado, los resultados obtenidos, de acuerdo a los objetivos que se deben alcanzar con el programa?

2.4 ¿De qué forma se asegura usted que el funcionario responsable (el director y el coordinador), de los centros educativos integrantes del programa, conocen lo que se espera de ellos, con respecto a la aplicación del programa?

\section{PARTE: Estructura de organización}

3.1 ¿En qué se basa para elaborar el organigrama, de modo que se visualice la división del trabajo en los centros educativos, en donde se desarrollará el programa?

3.2 Con respecto al organigrama de su supervisión, ¿qué aspectos o criterios tomó en cuenta para incorporar el programa y su implementación, para que lo visualicen los miembros de la supervisión?

3.3 ¿Cómo se desarrolla el Programa de Innovaciones en las distintas áreas académicas de las instituciones involucradas?

\section{PARTE: Proceso de planificación}

4.1 ¿De qué forma se incluye el programa, en el POA de las instituciones participantes?

4.2 ¿Cómo se asegura que los colegios participantes tienen el equipo y la infraestructura mínima requerida para desarrollar el programa?

4.3 ¿De qué manera ha interactuado con otras autoridades respectivas, para desarrollar el programa, de modo que se promueva la voluntad política requerida?

4.4 ¿Cómo procedió, en conjunto con la dirección de los centros educativos participantes, para desarrollar las directrices propuestas por el MEP, con respecto a la aplicación del programa?

4.5 ¿Cómo contribuyen los objetivos y metas propuestas por el programa, con los propuestos por cada uno de los tres centros educativos, como un todo?

4.6 ¿De qué forma combina usted con los directores respectivos, actividades tendientes a implementar un plan de acción tendiente a alcanzar los objetivos del programa, en las instituciones partícipes?

4.7 ¿Qué tipo de acciones realiza usted para prevenir inconvenientes que surjan durante la aplicación del programa, en las instituciones involucradas?

4.8 ¿De qué forma promueve usted la selección y promoción de la capacitación del funcionario responsable de la aplicación del programa, en cada una de las instituciones participantes?

4.9 ¿Cómo combina con los directores respectivos, desde la supervisión, la delegación de distintas tareas o funciones asociadas para cumplir los objetivos propuestos, respecto a la ejecución del programa?

4.10 ¿En cuál información se basa, desde la supervisión, para verificar y promover la realimentación, para mejorar la ejecución del programa, en los integrantes de los centros educativos participantes?

4.11 ¿De qué forma aplica usted acciones, para verificar que los resultados obtenidos, corresponden a los objetivos propuestos inicialmente por el programa en las instituciones participantes? 


\section{PARTE: Sistemas de control}

5.1 ¿Qué tipo de acciones o actividades implementa usted para inspeccionar la adecuada aplicación y cumplimiento de responsabilidades por parte del director, con respecto a la aplicación del programa en las instituciones participantes?

5.2 ¿De qué forma coordina con la Asesoría del MEP respectiva para monitorear la adecuada aplicación del programa en los centros educativos participantes?

5.3 ¿De qué manera el porcentaje de promoción del estudiantado de los centros educativos participantes, está relacionado con la aplicación del programa?

\section{PARTE: Estrategias de evaluación}

6.1 ¿De qué forma el informe o documento emitido por el responsable de la aplicación del programa en cada centro educativo participante, cumple con las expectativas de los objetivos planteados por el programa?

6.2 ¿Cuáles han sido los resultados obtenidos, con la implementación del programa, en cada una de las instituciones participantes?

Comentario:

¡Gracias por su colaboración! 


\section{Anexo D}

\section{Entrevista dirigida al asesor asignado al programa}

Universidad de Costa Rica

Sistema de Estudios de Posgrado

Facultad de Educación

Escuela de Administración Educativa

Por este medio solicito, respetuosamente, su colaboración para realizar una entrevista cuyo objetivo es analizar la gestión de las organizaciones educativas respecto de la implementación del Programa Nacional de Innovaciones Educativas en tres instituciones del circuito 09 de la Dirección Regional San José Norte. La investigación corresponde a un estudio de la Maestría en Ciencias de la Educación con énfasis en Administración Educativa. La información que usted proporcione, será completamente confidencial, y al mismo tiempo, tendrá un aporte invaluable, pues sin duda alguna contribuirá a fortalecer la calidad del sistema educativo público costarricense.

\section{Entrevista dirigida al asesor}

I PARTE: INFORMACIÓN GENERAL: Marque con una equis ("x") la opción que más se aproxima a su condición o complete los espacios en blanco según corresponda:

\begin{tabular}{|c|c|c|c|c|c|}
\hline 1.1 & $\begin{array}{l}\text { Formación original como docente: (por } \\
\text { ejemplo: profesor de matemática o español) }\end{array}$ & & $\begin{array}{l}\text { Sexo: } \\
\text { ( ) Masculino } \\
\text { ( ) Femenino }\end{array}$ & 1.3 & Edad: ___ años \\
\hline $\begin{array}{l}1.4 \\
1.5\end{array}$ & $\begin{array}{l}\text { Años de ejercer la docencia: } \\
\text { Años de experiencia de ejercer la función de } \\
\text { asesor:_años }\end{array}$ & 1.6 & $\begin{array}{l}\text { Grado académico } \\
\text { más alto: }\end{array}$ & 1.7 & $\begin{array}{l}\text { Año en que obtuvo } \\
\text { su último grado } \\
\text { académico: }\end{array}$ \\
\hline 1.8 & $\begin{array}{l}\text { Condición laboral en la Institución: } \\
\text { ( ) Propiedad ( ) Interino }\end{array}$ & 1.9 & Categoríaprofesional: & & \\
\hline
\end{tabular}

\section{PARTE: Mecanismos de coordinación}

2.1 ¿Cómo nació el Programa Nacional de Innovaciones Educativas?

2.2 ¿En qué se basa para la formación de equipos de trabajo que ejecuten el programa en las instituciones?

2.3. ¿De qué forma le comunicó tanto al director como al personal docente participante de las instituciones participantes, la aplicación y las pautas a seguir para implementar el programa? 
2.4 ¿Cómo desarrolla o promueve la fluidez y dinamismo de comunicación, durante la aplicación del programa entre el director y el funcionario responsable?

2.5 ¿Cómo asigna y monitorea las responsabilidades durante el desarrollo del programa?

2.6 ¿Se cuenta con una programación sobre la labor que debe realizar, con respecto a la aplicación del programa?

2.7 ¿Qué medios utiliza usted para comunicar al personal participante (tanto a nivel del MEP, como de los centros educativos participantes) los resultados, de acuerdo a los objetivos que se deben alcanzar con el programa?

2.8 ¿Cuentan las instituciones participantes con el personal idóneo para asignar las tareas que implica la aplicación del programa?

2.9 ¿Cómo se asegura que el funcionario responsable conoce lo que se espera de él, en el marco de la aplicación del programa?

2.10 ¿Cómo verifica que el funcionario responsable en cada centro educativo comparte su conocimiento y habilidades con el resto de sus compañeros, para alcanzar los objetivos propuestos en el programa?

\section{PARTE: Estructura de organización}

3.1 ¿Cuenta cada institución con un manual descriptivo de puestos, acorde con los objetivos que se desean alcanzar con la implementación del programa?

3.2 ¿Se manifiesta un organigrama en las instituciones que visualice la división del trabajo?, ¿cómo se procedió para su elaboración?

3.3 ¿Cómo se incorpora en el organigrama de las instituciones, el programa para que se visualice de forma clara ante los miembros del centro educativo?

3.4 ¿De qué forma se desarrolla el programa en las distintas áreas académicas de las instituciones?

3.5 ¿Qué criterios considera usted en la formación del comité u otro grupo que participe en el adecuado desarrollo del programa?

\section{PARTE: Proceso de planificación}

4.1 ¿De qué forma se incluye el programa en el POA de las instituciones?

4.2 ¿Cómo selecciona el personal idóneo e interesado para desarrollar los objetivos del programa?

4.3 ¿De qué forma canaliza usted con los distintos departamentos (o áreas académicas), la implementación del programa en las instituciones?

4.4 ¿De qué tipo de equipo de cómputo e infraestructura disponen los centros educativos para desarrollar el programa?

4.5 ¿Ha interactuado de alguna forma con otras autoridades para desarrollar el programa, de modo que se promueva la voluntad política requerida? 
4.6 ¿Cómo se han considerado los fines y objetivos del programa en la filosofía institucional de los centros educativos?

4.7 ¿De qué forma regula el desarrollo de las directrices propuestas por el MEP, con respecto a la aplicación del programa?

4.8 ¿Cómo contribuyen los objetivos y metas propuestas por el Programa de Innovaciones, en beneficio de los centros educativos?

4.9 ¿Cómo contribuyen los objetivos y metas propuestas por el programa, con los propuestos por los centros educativos, como un todo?

4.10 ¿Qué tipo de actividades utiliza usted para desarrollar un plan de acción, para lograr los objetivos del programa?

4.11 ¿Qué tipo de precauciones o previsiones toma usted en cuenta, ante la aplicación del programa?

4.12 ¿Cómo coordina usted con el centro educativo, los distintos requerimientos físicos que se necesitan para el desarrollo del programa?

4.13 ¿De qué forma coordina con otra autoridad competente del MEP, la asignación del funcionario idóneo que aplique adecuadamente el programa?

4.14 ¿En cuáles criterios se funda para seleccionar y promover la capacitación del funcionario responsable del programa?

4.15 ¿Cómo aplica la delegación de distintas tareas relacionadas con la ejecución del Programa, según los objetivos propuestos?

4.16 ¿En cuál información se basa para verificar y promover la realimentación, para mejorar la ejecución de la innovación propuesta por el programa, en los miembros de los centros educativos participantes?

4.17 ¿Cuáles acciones realiza usted para monitorear que los resultados obtenidos de la aplicación del programa, corresponden con los resultados deseados?

\section{PARTE: Sistemas de control}

5.1 ¿Qué tipo de acciones o mecanismos usa para monitorear la adecuada aplicación y cumplimiento de responsabilidades por parte del personal responsable (en cada centro educativo), con respecto a la aplicación del programa?

5.2 ¿Cómo coordina con el director y/o funcionario responsable, para verificar o monitorear la adecuada aplicación del programa?

5.3 ¿De qué forma el porcentaje de promoción del estudiantado refleja lo esperado, con respecto a la aplicación del programa? 


\section{PARTE: Estrategias de evaluación}

6.1 ¿Se cuenta con un sistema de evaluación exclusivo para el alumno que participe directamente en el programa?, ¿por qué?

6.2 ¿El informe o documento emitido por el responsable de la aplicación del programa en los centros educativos, cumple con las expectativas de los objetivos planteados?

6.3 ¿Cuáles han sido los resultados obtenidos, con respecto a la implementación del programa en las instituciones?

Comentario:

¡Gracias por su colaboración! 